Electron Beam Welding and Characterization of 21-6-9 Stainless Steel Annealed Plate and Welds

J. W. Elmer, D. Hiromoto, C. Evans, J. Florando,

I. Golosker

December 4, 2012 
This document was prepared as an account of work sponsored by an agency of the United States government. Neither the United States government nor Lawrence Livermore National Security, LLC, nor any of their employees makes any warranty, expressed or implied, or assumes any legal liability or responsibility for the accuracy, completeness, or usefulness of any information, apparatus, product, or process disclosed, or represents that its use would not infringe privately owned rights. Reference herein to any specific commercial product, process, or service by trade name, trademark, manufacturer, or otherwise does not necessarily constitute or imply its endorsement, recommendation, or favoring by the United States government or Lawrence Livermore National Security, LLC. The views and opinions of authors expressed herein do not necessarily state or reflect those of the United States government or Lawrence Livermore National Security, LLC, and shall not be used for advertising or product endorsement purposes.

This work performed under the auspices of the U.S. Department of Energy by Lawrence Livermore National Laboratory under Contract DE-AC52-07NA27344. 


\title{
Electron Beam Welding and Characterization of 21-6-9 Stainless Steel Annealed Plate and Welds \\ by:
}

\author{
John W. Elmer, G. Fred Ellsworth, Jeff N. Florando, Dave S. Hiromoto, \\ Cheryl L. Evans, and Ilya V. Golosker
}

September 27, 2012

\section{Summary}

This report summarizes the electron beam (EB) welding and characterization work performed on annealed 21-6-9 stainless steel plate during the 2011-2012 time period. The work was directed at producing legacy autogeneous EB welds with the use of the Enhanced Modified Faraday Cup (EMFC) EB diagnostic to characterize the beam, and measuring the resulting tensile and hardness properties of the weld relative to annealed 21-6-9 stainless steel base metal. Different tensile bar configurations were produced, and the results were analyzed to determine how well the stress-strain behavior of small tensile samples compares to standard sized tensile samples for the same material. Additional comparisons were made between cross-weld tensile samples with and without weld steps to determine how the unwelded portion of a step joint affects the measured tensile behavior. Base metal tensile data was further used to calibrate a spherical indentation method to estimate uniaxial tensile behavior using a nanoindenter. The calibrated method was then used to generate the first engineering stress-strain curve for EB welded 21-6-9 stainless steel. Additional analysis was performed to determine Steinberg-Guinan and Johnson-Cook model parameters to represent both the annealed 21-6-9 SS base metal and the EB weld metal stress-strain behaviors under quasi static strain rate conditions.

\section{Introduction}

Alloy 21-6-9 stainless steel (SS), known as Nitronic 40 and further designated as UNS S21900, was developed as an improved austenitic stainless steel over traditional $18 \% \mathrm{Cr}-8 \% \mathrm{Ni} 300$ series stainless steel alloys. $21-6-9$ SS contains nominally $21 \% \mathrm{Cr}, 6 \% \mathrm{Ni}, 9 \% \mathrm{Mn}$, and has improved corrosion resistance due to its higher $\mathrm{Cr}$ content of $21 \%$. In addition, 21-6-9 SS uses $\mathrm{N}$ rather 
than $\mathrm{C}$ as a strengthener, which reduces the tendency for corrosion sensitization that can occur during heat treating and welding. Nitrogen can be added up to $0.35 \%$, which improves the room temperature yield strength of 21-6-9 SS over 300 series stainless steel alloys, while maintaining good toughness and high ductility (>40\%). Manganese is added to 21-6-9 SS to increase austenite stability, particularly at cryogenic temperatures, while reducing the $\mathrm{Ni}$ content from $8 \%$ to $6 \%$ as compared to 300 series stainless steels. 21-6-9 SS can be further strengthened by cold work and can be machined, forged, and welded using the same methods as 300-series stainless steels. Due to its higher strength, excellent corrosion resistance, and ease of fabrication, 21-6-9 SS is an ideal material where multiple parts need to be produced and joined by fusion welding to create the required shape. Since welding can alter the properties of the base metals being joined, this report discusses the mechanical properties of the 21-6-9 SS and the effects of welding on quasi-static stress-strain, and hardness behavior of welds relative to the base metal properties. A review report on characterization of 21-6-9 SS base metal can be found in Ref [1], and its yield stress over a wide range of strain rates and temperatures can be found in Ref [2].

\section{Material and Experimental Procedures}

\section{Materials}

Annealed 21-6-9 SS plate was acquired from LLNL WR certified material storage. The composition of the plate is summarized in Table 1, where the measured "actual" composition of this plate is compared to the commercial "specification", the LLNL "Guarantee", and the LLNL desired "Aim" composition range for weldability. The LLNL requirements are from specification RM254700-000 for electroslag remelted cross rolled plate, which has a stringent requirement over control of nitrogen for improved electron beam weldability. The alloy falls within the LLNL guaranteed composition range for all elements except silicon, which is lower than the guarantee range, but meets the LLNL AIM requirement. The initial plate measured $3 \mathrm{~mm}$ thick and was further machined to the size of $100 \times 200 \times 1.5 \mathrm{~mm}$ for base metal material property testing. Ferrite measurements were made on the base metal using a Magne-Gage tester and a number 3 magnet, showing that the base metal had no measurable ferrite. After welding, the ferrite content was measured on polished cross sections and on the top of the electron beam weld beads, showing that the welds contained delta ferrite that measured between 0.8 to $1.1 \%$. However, due to the small weld volume ( $1 \mathrm{~mm}$ deep, $1.5 \mathrm{~mm}$ wide), the magnetic measurements may underestimate the actual ferrite content of the weld by as much as $5 \mathrm{X}$ due to incorporation of the zero percent base metal ferrite into the readings. 


\section{Electron Beam Welding}

Samples to be welded were machined to the size of $50 \times 200 \times 1.5 \mathrm{~mm}$, so that when welded along their length they would have the same dimensions as the base metal samples. The weld joint preparation was a step joint configuration, as documented in LLNL drawings AAA10502549 and AAA10-502550, which has a step height requiring $1 \mathrm{~mm}$ weld penetration. Electron beam welds were made using LLNL electron beam welder \#605 (blue welder) to match legacy parameters that used a defocused beam. Note that only the penetration pass was made on these welds, and that no cosmetic passes were made. All welds were made with a 9 inch work distance, and performed at $4 \times 10^{-5}$ torr vacuum. The LLNL Enhanced Modified Faraday Cup (EMFC) electron beam diagnostic was used to measure the properties (peak power density, full width half maximum, beam diameter, and beam aspect ratio) of each beam prior to welding using the method detailed elsewhere $[3,4]$.

\section{Tensile Testing}

The base metal and welded plates were electro discharge machined (EDM) into two different sized tensile bars as illustrated in Figure 1. The "standard "tensile bars measured 4 inch long per drawing AAA11-501227, Tab-01, and are based on an ASTM E-8 tensile sample with a length-to width ratio of 4:1. The "mini" tensile samples were $2 / 5$ size and maintained the same 4:1 length to width ratio as illustrated in drawing AAA11-501227, Tab-02. A portion of the $4 \times 8$ inch plate was reserved for biaxial bulge testing, but these tests have not been completed. Tensile bars removed from the welded plate are cross-weld tensile samples, since all-weld, longitudinal, tensile bars were not able to be prepared due to the small volume of welded material. The welded tensile samples were further prepared using two methods as illustrated in Fig. 2. The first method used the tensile bar in the full-thickness $(1.5 \mathrm{~mm})$ as welded condition, i.e., with an unwelded portion of joint directly below the step joint. The second method prepared the welds by machining the top and bottom surfaces of the welded sample to a final thickness of $0.75 \mathrm{~mm}$ so as to remove any weld reinforcement and undercut on the top surface and the unwelded portion below the step. Cross sectional areas of the samples were measured, to calculate the stress, on each sample to account for any variations in machining that may have occurred.

The Tab-02 "mini" sample tests were performed in an Instron 4444 electromechanical test machine at room temperature and position control at a rate of $0.020 \mathrm{in} / \mathrm{min}$. A Shepic strain extensometer with a gage length of 0.225 inch $-50 \%$ was used to measure strain for the Tab-02 parent and milled weld mini-tensile samples, while a 0.138 inch gage length was used on the full thickness mini samples. In all cases the knife edges of the extensometer were located across the width of the sample and centered over the weld. The Tab-01 "standard sample" tests were performed in an Instron 5800R/4505 test machine at room temperature and 
position control at a rate of $0.050 \mathrm{in} / \mathrm{min}$. An EIR LE-01 laser extensometer with a 1 inch gage length was used to measure strain for the Tab-01 standard sized samples, with the gage length centered over the weld, and with the laser facing the top (weld side) of the sample. The laser measured the extension of two dimples on the sample that defined the gage length. The modulus of elasticity was determined by the best fit straight line through the linear portion of the stress-strain curve, the yield strength was determined using a $0.2 \%$ offset method, and the ultimate tensile strength was determine by the peak load divided by the load bearing area. Additional details and photographs of the testing setup can be found in [5].

\section{Metallography, Microhardness, and Nanoindentation Testing}

Metallographic cross sections of the welds and base metals were performed using standard preparation procedures in the B231 microstructural characterization laboratory. The samples were sectioned on a slow speed diamond saw, potted in a clear two-part epoxy, and then ground on successive silicon carbide papers from 320 to 2400 grit. The samples were polished first using 3 micron diamond paste, followed by a 1 micron alumina slurry. The samples to be etched were electrolytically etched in a 5-10\% oxalic acid solution at room temperature to bring out the microstructure. Macrophotographs of the entire weld fusion zone shapes were made using a Keyence VHX-600E Digital Microscope, while higher magnification micrographs were made using a Reichert inverted stage metallograph.

Vickers microhardness testing was performed on a calibrated Leco AMH43 microhardness testing system with load range from 1 to $500 \mathrm{gm}$. The indentations were made using a $50 \mathrm{gm}$ load, and were manually measured using a 50x objective to determine the Vickers Hardness indentation diagonal lengths, which were typically about 20 microns corner to corner.

Nanoindentation hardness testing was done using a spherical indenter to measure load-depth curves that could be converted into approximate stress-strain material behavior. This method was particularly useful for estimating the stress-strain behavior of the welds, since the fusion zones were too small for a standard tensile test method. The 21-6-9 SS samples (polished, but not etched, base and weld metal) were testing in the B231 G200 Nanoindenter from Agilent. A 50 micron radius spherical diamond tip was used during these tests. The advantages of this nanoindenter are that it has high load and displacement resolution, on the order of $50 \mathrm{nN}$ and 1 $\mathrm{nm}$ respectively, and with the high load option can go up to $10 \mathrm{~N}$ of force. Due to the relatively large diameter of the sphere coupled with the high strength of 21-6-9 SS, the high load option was used for these tests. In addition, this nanoindenter can apply an oscillating signal on top of the load signal which permits the stiffness of the material to be measured continuously (CSM) 
as a function of depth. All the tests were run using the high load and CSM options to measure the stiffness which is used in the calculation of stress and strain.

\section{Electron Beam Welds and Microstructure}

Electron beam welds were developed to match the exact heat input, and approximate defocus of legacy welds. The welds were made using $110 \mathrm{kV}, 5.5 \mathrm{~mA}(605 \mathrm{~W})$ at a weld speed of $60 \mathrm{ipm}$, however the amount of defocus was considered a variable since the legacy welds were made on different electron beam welders with different focusing response. The welds in this study were made with defocus settings of $+35,+40$ and $+45 \mathrm{~mA}$ relative to the sharp focus setting of $725 \mathrm{~mA}$, which bracket the legacy welds by $+-5 \mathrm{~mA}$ of defocus. The resulting initial welds are summarized in Fig. 3, which shows the results of the EMFC beam diagnostic alongside the cross sectional weld pool shape. As predicted, the weld penetration increased with lower defocus settings as the beam dimensions reduced and the peak power density increased. The only weld that met the minimum penetration requirement to the bottom of the step was the weld defocused the least amount at $+35 \mathrm{~mA}$. Based on the results of these three welds, a target parameter range was established for a +35 mA defocused to have a peak power density of 1.5$1.6 \mathrm{~kW} / \mathrm{mm}^{2}$, a beam diameter of 0.90-1.0 mm, and a beam FWHM of 0.50-0.55 mm. These data became the target data for the remaining welds that were made for tensile testing.

The final set of six welded step joint pairs was made on the same electron beam welder that was used to make the development welds, with individual pumpdowns for each weld. The welding parameters were also the same as the development welds, namely, $110 \mathrm{kV}, 5.5 \mathrm{~mA}$ (605 W) beam, a weld speed of $60 \mathrm{ipm}$; however, the focus setting was adjusted as required to maintain the beam parameters within the target value ranges. A typical beam profile that meets these requirements is shown in Fig. 4. This beam produced a weld that had the desired penetration and the geometric shape of a typical legacy weld, as shown in Fig. 5, weld 3. Note that the beam is not circular at this level of defocus on this EB machine, and has an elliptical shape with an aspect ratio of approximately 1.8:1. The elliptical beam shape is believed to be the cause of the undercut on one side of the weld.

A summary of the EB welding parameters, weld penetrations, and weld widths is presented in Table 2. The weld penetrations varied from 0.98 to $1.14 \mathrm{~mm}$, while the weld widths across the top surface varied from 1.51 to $1.56 \mathrm{~mm}$. Metallographic cross sections of each of the six welds are shown in Figure 5, indicating that the welds are reasonably uniform in shape, and that all of the welds met the penetration requirement and were free of pores and cracks. Undercutting appears on one side of the top surface that measures $52.7 \pm 5.4 \mu \mathrm{m}$. The maximum undercut 
was measured to be $58 \mu \mathrm{m}$, leaving at least $0.800 \mathrm{~mm}$ of full weld fusion zone above the step for removal of the $0.750 \mathrm{~mm}$ thick milled tensile samples.

At high magnifications, the 21-6-9 SS weld microstructure was shown to be considerably different than the base metal microstructure. Fig. 6a shows the base metal microstructure which has consists of equiaxed grains that have an average grain diameter of approximately 50 $\mu \mathrm{m}$. Annealing twins are present in many of the grains, and small inclusions are randomly dispersed. The base metal microstructure is banded due to the effects of chemical segregation during ingot casting and subsequent hot working and rolling. The chemical segregation is typical of 21-6-9 SS WR plate. No delta ferrite was observed or measured in the base metal portions of the samples. The weld microstructure is shown at the fusion boundary in Fig. $6 \mathrm{~b}$ and in the central portion of the fusion zone in Fig. $6 \mathrm{c}$. The microstructure consists of austenite (light etching phase) with some remnant delta ferrite (dark etching phase). The majority of the microstructure appears to have formed by the solidification of primary ferrite with second phase austenite (FA) mode where the primary ferrite dendrites that form during solidification partially transform to austenite during cooling [6]. The remaining vermicular/skeletal ferrite is concentrated at the original cores of the ferrite dendrites, and represents only a small fraction of the original primary ferrite phase that formed.

Figure 7a shows a higher magnification micrograph of the fusion boundary, where the remaining ferrite can be seen more clearly, and represents about 3-5\% of the fusion zone microstructure in this location. Epitaxial regrowth of austenite from the base metal $(1-2 \mu \mathrm{m})$ is followed by a zone ( $10 \mu \mathrm{m})$ that is difficult to interpret and initially may be the AF solidification mode, which then transitions to the FA mode of solidification deeper into the fusion zone. Also note the grain boundary ferrite that formed near the heat affected zone (HAZ) at the upper left portion of the fusion zone. Figure $7 \mathrm{~b}$ shows a higher magnification micrograph near the center of the fusion zone, which clearly solidified in the FA mode with skeletal ferrite present throughout the majority of the microstructure, and lacy ferrite [6] present in the upper right hand side of the micrograph. The ferrite content appears to vary between about $5 \%$ and $15 \%$ depending on the local ferrite morphology. The higher amount of ferrite observed in the microstructure relative to that measured by the Magne-gage $(\sim 1 \%)$ is related to the inherent error of measuring ferrite with the Magne-gage on small weld samples that incorporate base metal ( $0 \%$ ferrite) into the reading. 


\section{Mechanical Properties of the Base Metal and Welds}

\section{Microhardness of the Base Metal and Weld Fusion Zones}

Table 3 summarizes the microhardness measurements that were made on the base metal, the electron beam fusion zone, and the HAZ for each of the 6 welded coupons. A total of 36 hardness measurements were made on the base metal samples, showing that the base metal had an average hardness of $212.1 \pm 10.9 \mathrm{HV}$. These values correspond to annealed 21-6-9 SS sheet, which has a handbook value of RB 94 (HV 213) [7]. After welding, the fusion zone hardness was measured at 254.4 $\pm 9.7 \mathrm{HV}$ based on 62 measurements made in the 6 welds. Figure 8 provides additional statistics about the hardness measurements in a quartile plot, showing that the $20 \%$ increase in hardness after welding is statistically significant and clearly indicates that the weld is strengthened relative to the 21-6-9 SS base metal due to its fine twophase solidification structure as described above.

Additional microhardness measurements were made in the HAZ of the welds by placing the indenter in the base metal at a distance of 1-2 indentation distances (20-40 micron) from the weld fusion line. The resulting measurements showed HAZ hardness values midway between the weld fusion zone and the base metal of $232.1 \pm 13.9 \mathrm{HV}$, with statistical outlier data points as indicated in Fig. 8. The apparent strengthening of the HAZ is more likely due to the indentation being artificially affected by the nearby harder weld metal than an actual increase in hardness of the HAZ, based on the belief that there should be no HAZ hardening mechanisms in the annealed 21-6-9 SS heat affected zone.

\section{Stress-Strain Behavior of Cross-Weld Tensile and Base Metal Samples}

The base metal and two different types of cross-weld samples were tensile tested to failure in both standard ( 4 inch long) and mini (1 inch long) configuration dog-bone shaped samples. Figure 9 shows the failure behavior for each of the six different tensile bar configurations. The parent metal samples for the mini (a) and standard (d) tensile configurations failed approximately in the middle of the gage length with necking occurring mostly through the thickness of the bars. The welded samples that were milled to remove the effects of the unwelded step and weld reinforcement for the mini (b) and standard (e) tensile configurations failed approximately half-way between the weld and the radius that forms the tensile grips. In both cases a "lump" of weld metal is left behind where the stronger weld fusion zone deforms less than the base metal away from the weld. The final failures have a similar necking appearance to the base metal samples. The welded samples that were pulled in the fullthickness condition for the mini (c) and standard ( $f$ ) tensile configurations failed in a completely different manner. Due to the reduced amount of load bearing material above the step, the 
samples failed in the base metal close to the weld, tearing through the base metal with less apparent necking and less measured strain to failure than the other samples.

Figure 10 shows close up photos of the necked regions of the broken mini tensile samples. The parent metal sample is shown in (a) and (b) for the side and top views of the fractured sample respectively. Thinning of the sample through the thickness and across the width of the sample is apparent. The failure is ductile in appearance, and final failure occurred with the formation of a shear lip at approximately 45 degrees to the tensile axis. The milled cross-welded sample is shown in (c) and (d) for the side and top views of the fractured sample respectively. The weld location is marked in the figures and it is clear that the fracture occurred well away from the weld. It can also be seen that the weld region deformed less than the base metal, being wider and thicker than the adjacent base metal. Just like the base metal sample, the failure is in the base metal and the final failure occurred with the formation of a shear lip at approximately 45 degrees to the tensile axis. The full-thickness cross-weld sample is shown in (e) and (f) for the side and top views of the fractured sample respectively. The cross section shows that the location of the failure is clearly adjacent to the fusion line of the weld in the reduced thickness portion of the sample. As before the final failure is ductile in appearance, forming a 45 degrees shear lip relative to the tensile axis. Some localized deformation extends from the base of the weld and appears to follow a columnar weld grain boundary into the weld fusion zone. The top view of the failed sample shows narrowing occurring on the side of the weld with the reduced section thickness, and little to no narrowing on the thick section side of the weld.

This same sample was then polished and etched to show the deformation and failure locations more clearly. Figure 11a shows the sample lightly polished and etched, indicating that the weld region above the step is deforming, while the remainder of the weld appears relatively unstrained. Figure $11 \mathrm{~b}$ shows the same sample after lapping more deeply below the surface and then repolishing and etching, showing that the final failure occurred in the base metal adjacent to the fusion zone. A high magnification photo of the failed region adjacent to the fusion line is shown in Fig. 11c. The individual base metal grains near the fusion line contain wavy deformation bands. These bands are likely caused by strain-induced martensite, which forms during deformation and is known to be the principal strain hardening mechanism in stainless steels [8] and is also known to form in 21-6-9 SS at high strain rates [9]. Microhardness measurements made in necked region of the failed sample showed that the hardness is $394.8+12.0 \mathrm{HV}$ for 9 data points, which is considerably harder than the undeformed base metal (212.2 HV) or the weld (254.4 HV).

Figure 12 plots the uniaxial engineering stress versus engineering strain tensile behavior of the parent metal samples for both the mini and standard tensile configurations, and the resulting data are summarized in Table 4. Except for one sample that was pre-strained and showed 
higher yield stress, the parent metal tensile samples showed yield stresses $\left(\sigma_{y}\right)$ that varied from 50.0 to $53.0 \mathrm{ksi}$, with the mini tensile bars having yield strengths on the lower end of this range. All curves show significant strain hardening with ultimate tensile strengths (UTS) varying between 101.6 to $105.2 \mathrm{ksi}$, with the mini tensile bars on the upper end of this range. The elongations at failure varied from $47 \%$ to $62 \%$ for the parent metal samples using the laser extensometer with the 1 inch gage length. The mini samples, with the smaller 0.225 inch gage length, showed elongations from $50 \%$ to more than $80 \%$. Note that the extensometer was removed prior to failure of the mini samples, resulting in the small load drop observed in the plotted curve. The subsequent stress-strain behavior after the extensometer was removed was estimated from the load versus crosshead displacement measurements, which is an approximation that doesn't match the strain hardening rate measured by the extensometer.

Figure 13 plots the results of the milled weld samples plotted as engineering stress versus engineering strain. These samples behaved nearly identically to the parent metal samples with yield strengths varying from 52.8 to $55.7 \mathrm{ksi}$, and ultimate strengths varying from $103.9 \mathrm{ksi}$ to $105.8 \mathrm{ksi}$ as summarized in Table 4. The elongations to failure for the standard sized samples were similar to those of the parent metal, varying from $57 \%$ to $63 \%$, while those for the mini samples again displayed higher elongations due to the smaller gage length. Observations of the tensile samples showed that in all cases, the milled weld cross tensile samples failed in the base metal due to the higher strength of the weld. Because of this, the yield and ultimate strengths measured on these samples essentially match those of the parent metal samples.

Figure 14a plots the engineering stress versus engineering strain results of the full thickness welded samples, where the weld reinforcement and unwelded portion of the step were not removed. The tensile behavior is quite different than for the milled cross-weld tensile samples. Yield strengths, based on the area of the sample above the weld step, were considerably higher than the other samples with values of $76.0 \mathrm{ksi}$ for the standard samples, and values between 67.0 and $75.5 \mathrm{ksi}$ for the mini samples. This data is $25-43 \%$ higher than the other samples. The difference in behavior can be explained with the aid of Fig. 14b that schematically illustrates the full thickness test sample. In this sample, there is a region of high strain concentration directly above the unwelded step, which contains a large fraction of welded metal. The higher yield strengths measured on the full thickness samples are partly based on the fact that the majority of the high strain region contains higher strength welded metal. However, additional factors due to the localization of strain caused by the change in cross sectional areas, and sample bending, may be contributing to the increased yield strength. Note also from the weld cross sections in Fig. 5, that the fraction of weld metal in the high strained region is not constant, and may contribute to sample-to-sample variability in the measured yield stress. The measured elongations were also different than the milled cross-weld samples. The standard sized fullthickness cross-weld samples all failed with total elongations of only $10 \%$, while the mini 
samples failed between $22 \%$ and $27 \%$ elongation. The reduced elongations are likely to be the direct result of the strain localization, and the fact that the extensometers span a much wider area than the highly strained region. Peak loads were used to calculate the UTS based on the reduced cross sectional area of the sample above the unwelded portion of the step, showing values between 102.3 and $110.2 \mathrm{ksi}$, which are similar to the tensile tests in the other sample geometries. Note that the measured modulus data for the full thickness samples is not accurate due to the change in section thickness and possible bending of the samples. This effect is magnified with the shorter gage length mini sample where a larger fraction of necking is present in the gage length.

In summary, the tensile test results show that the cross-weld samples failed in the parent metal portions of the tensile bar, and produced strengths comparable to the all parent metal samples having a $0.2 \%$ offset yield strength of $53.1 \pm 1.9 \mathrm{ksi}$, an ultimate strength of $105.3 \pm 2.2 \mathrm{ksi}$, and a Young's modulus of $29.4 \pm 0.95 \mathrm{Msi}$. The engineering strain at failure measured on the standard sized samples with a 1 inch gage length was approximately $60 \%$, while the mini samples for both the parent metal and the milled cross-weld configurations, had higher measured elongations due to the larger fraction of necked region in the 0.225 inch gage length. The fullthickness cross-weld tensile samples, showed highly localized strain behavior in the reduced thickness portion of the step welded joint. The associated change in thickness near the weld resulted in a reduced engineering strain at failure, higher yield strengths (73.4 $\pm 3.9 \mathrm{ksi})$, and similar UTS measurements as the other tensile test samples and configurations.

\section{Nanoindentation Estimation of the Stress-Strain Behavior of the Welds}

Uniaxial tension or compression testing is the standard method to obtain stress-strain data. However, there are times when the specimen or feature size is approaching dimensions that make it difficult to perform standard tests, as is the case for the small electron beam welds studied here. An alternate method that can be used to measure the stress-strain behavior of small welds relies on an indentation technique. During indentation, the hardness of a material, defined as the load/area, is measured. The stress state during indentation however is much more complicated than in a uniaxial test and can be influenced by the shape and material of the indenter [10]. During spherical indentation, the plastic zone develops gradually, allowing for the elastic-plastic transition to be probed in order to produce an indentation stress-strain curve. The spherical indentation method is used here to estimate the stress-strain behavior of the welded region of a 21-6-9 SS part, using the base metal, with known tensile behavior, for calibration. 
The base metal and electron beam welded samples were metallographically prepared and tested in the as-polished condition. The loading rate was $50 \mathrm{~nm} / \mathrm{s}$ for each indent to a depth of $7000 \mathrm{~nm}$, which corresponds to a strain rate of about $1 \times 10^{-4} / \mathrm{s}$. These parameters were selected to match the strain rate of the standard tensile tests from the previous study, and reach a strain of about $10 \%$. In order to convert the load, displacement, and stiffness data from the indentation test to indentation stress and strain, the following calculations were used, which follows the procedure [11]. The contact depth, $h_{c}$ is calculated as:

$$
h_{c}=h-0.75 \frac{P}{S}
$$

where $\mathrm{h}$ is the displacement, $\mathrm{P}$ is the load, and $\mathrm{S}$ is the contact stiffness, all which is taken directly from the nanoindenter. From the contact depth, the contact radius, $a$ is

$$
a=\sqrt{2 h_{c} R_{i}-h_{c}^{2}}
$$

where $R_{\mathrm{i}}$ is the radius of the indenter. The indentation strain, $\varepsilon$, is defined as:

$$
\varepsilon=\frac{h_{c}}{2.4 a}
$$

And the indentation stress is:

$$
\sigma_{i n d}=\frac{P}{\pi a^{2}}
$$

To relate the indentation stress to the uniaxial stress the Tabor relationship is used where

$$
\sigma_{\text {uniaxial }}=\frac{\sigma_{\text {ind }}}{T}
$$

where $\mathrm{T}$ is the Tabor factor that can be estimated by correlating the indentation load displacement curve with a known uniaxial stress-strain curve of the material.

For calibration, the samples were first indentation tested in the base metal and then compared with the uniaxial tension tests reported here and originally from [5]. The data from the spherical indentation test was then converted to an indentation stress and indentation strain using the procedure described above. The correlation factor (Tabor relationship), to relate the indentation stress to the equivalent uniaxial stress, was then determined by matching to the uniaxial tests. This correlation factor was then used in calculated the corresponding stressstrain data for the weld sample. The main assumption is that the correlation factor is roughly 
the same between the base metal and the welded 21-6-9 SS. In addition, estimates of the elastic modulus were determined from the CSM readings, showing that the base metal had a modulus of elasticity of 198.2 $\pm 1.62 \mathrm{MPa}$ (six samples), and the weld had a modulus of elasticity of $190.1 \pm 1.86 \mathrm{MPa}$ (four samples). The nanoindentation results for the base metal compare well with the modulus values measured here in uniaxial tension of 202.7 $\pm 6.6 \mathrm{MPa}$ (12 samples). However, the modulus of the weld measured by nanoindentation is statistically lower. The reason for the lower measured modulus of the weld is unclear at this point and will require additional analysis to determine if this is a real effect or an artifact of the nanoindentation test results.

Representative indenter-based stress-strain curves for the base metal are shown in Figure 15. In order to match the data, a Tabor factor of 3.6 was applied. The spherical indentation data shows an initial overshoot in the stress before comes back down to match the uniaxial data. This overshoot is most likely due to the fact that we are probing a smaller volume with the nanoindenter and therefore require a higher stress in the initial part before enough dislocations are generated to accommodate the strain. The analysis and Tabor factor was then used to create the indenter-based stress-strain data for the welded region, as shown in Fig. 16, and a comparison between the base metal and weld region is shown in Fig. 17. The yield stress for the weld region is clearly higher as a result of its refined microstructure. The strain hardening rate, however, is the same between the two types of materials, which suggests that the scale for the hardening mechanisms, such as dislocation interactions, are smaller than the grain size of the weld region.

To extrapolate the indentation data to larger strains, the Steinberg-Guinan model was used to fit the indentation data [12]. The Steinberg-Guinan relationship is defined as:

$$
Y=Y_{o}\left[1+\beta\left(\varepsilon+\varepsilon_{i}\right)\right]^{n} \frac{G(P, T)}{G_{o}} \leq Y_{\max }
$$

where $Y_{0}$ is the yield stress, $\beta$ is the hardening coefficient, $n$ is the hardening exponent, $G_{0}$ is the reference shear modulus, $G(P, T)$ is temperature and pressure dependent shear modulus, and $Y_{\max }$ is the saturation stress representing the upper limit for the flow stress. For the experiments performed in this study the ratio of the shear moduli was assumed to be 1 . Since the indentation stress-strain curve stops at around 10\%, an additional data point was used to help constrain the fit. The additional data point is based on the Vickers microhardness results shown in Table 3, where the measured hardness for the base metal is $2.08 \mathrm{GPa}$ [GPa=9.8*HV/1000] and for the weld metal is $2.49 \mathrm{GPa}$. Using the standard Tabor factor of 3.6 for a sharp Vickers indent, the flow stress at $8 \%$ strain should be around $590 \mathrm{MPa}$ for the base metal and $700 \mathrm{MPa}$ for the weld. 
As a point of reference, there are published parameters for the Steinberg-Guinan model for 216-9 SS [13]. Since the published values are optimized for higher strain rates and SteinbergGuinan is a rate independent model, it is expected that the published 21-6-9 SS parameters [13] would over predict the strength in comparison to the quasi-static experimental data. Figure 19 shows the over prediction of the stress-strain behavior for the published Steinberg-Guinan data when compared to one of the experimental uniaxial stress strain curves for the base metal from this study. Clearly, the Steinberg-Guinan published data need to be reevaluated for quasi-static strain rates. This was done by both fitting the base metal uniaxial stress-strain curves, and the nanoindentation results using the MIDAS framework [14]. Fits were made out to 0.45 strain and passing through the appropriate points at $8 \%$ strain and are shown in Fig. 19. The same approach was used to fit and extrapolate the nanoindentation results for the electron beam welded material, and these results are plotted on Fig. 19 for comparison, showing the increased strength of the electron beam welds relative to the annealed 21-6-9 SS base metal. The Steinberg-Guinan model parameters for the base metal and weld are summarized and are compared to the published value [13] for 21-6-9 SS in Table 5.

An additional strength model that is commonly used is the Johnson-Cook strength relationship [15]. While also empirically based, there are additional terms which attempt to take into account the dependence on the strain rate and temperature, and the Johnson-Cook model has the following form:

$$
Y=\left(A+B \varepsilon^{n}\right)\left(1+C \ln \frac{\dot{\varepsilon}}{\dot{\varepsilon}_{o}}\right)\left(1-T^{* m}\right)+C_{p} p
$$

and

$$
T^{*}=\frac{T-T_{\text {room }}}{T_{\text {melt }}-T_{\text {room }}}
$$

where, $A$ is the effective yield stress at the reference strain rate, $\varepsilon^{\prime}{ }_{\circ}(1 / s)$ and temperature $\left(T_{R T}\right), B$ is a strain hardening coefficient, $n$ is the hardening exponent, $C$ is the coefficient for the strain rate term, $\mathrm{m}$ is the exponential for the temperature dependence, and $\mathrm{Cp}$ is the pressure coefficient, and $p$ is the actual pressure. The results of the Johnson-Cook model are compared to Steinberg-Guinan in Fig. 19, showing that both approaches can be used to represent the quasi-static uniaxial stress-strain behavior of 21-6-9 SS base metal and EB welds. The fitting parameters for Steinberg-Guinan and Johnson-Cook are summarized in Table 5 and Table 6 respectively.

In summary, spherical indentation with a nanoindenter can be used to measure the indentation stress strain behavior of 21-6-9 SS base metal and EB welds. The advantage for this technique is that the approximate stress-strain behavior can be measured using small amounts of 
material, such as welds. The main assumption in converting the indentation stress-strain behavior to uniaxial data is knowing the Tabor factor. For the 21-6-9 SS tested here, a Tabor factor of 3.6 was used, which matches the base metal indentation data to previous uniaxial tests. In comparing the measured stress-strain behavior between the base metal and the weld region, the weld shows a higher yield stress, but the strain hardening rates are similar, suggesting similar hardening mechanisms.

\section{Conclusions}

Legacy electron beam welds were made in annealed 21-6-9 SS flat plates that matched the desired penetration and weld fusion zone geometry. The EMFC electron beam diagnostic was used to characterize and control the EB parameters for weld consistency within this study, and for duplication of these parameters in the future. The measured electron beam parameters suggest that the beams should fall in the target range for peak power density of 1.5-1.6 $\mathrm{kW} / \mathrm{mm}^{2}$, beam diameter of 0.90-1.0 mm, and beam FWHM of 0.50-0.55 mm. This beam produces a $1.04 \pm 0.07 \mathrm{~mm}$ deep weld in $1.5 \mathrm{~mm}$ thick $21-6-9$ SS step joints at a welding speed of $60 \mathrm{ipm}$.

Metallographic characterization of the welds showed that they solidified with a two-phase microstructure consisting of austenite plus 5-10\% residual delta ferrite. The primary mode of solidification was ferrite (FA), followed by solid state transformation of the majority of the ferrite to austenite during cooling. The resulting microstructure is skeletal ferrite with some lacy ferrite observed near the center of the weld. Magne-gage measurements of the ferrite content proved to be inaccurate due to the small physical dimensions of the EB welds. Microhardness measurements were performed in the base metal and in the fusion zone of the welds, showing that the welds were statistically harder (254.4 $\pm 9.7 \mathrm{HV})$ than the annealed base metal $(212.1 \pm 10.9 \mathrm{HV})$. The higher hardness of the weld is due to its fine two-phase solidification microstructure relative to the equiaxed large grained base metal.

Uniaxial tensile testing was used to measure yield strength, ultimate strength, and elongation to failure of the base metal, and the same for cross-weld tensile samples. Two different dogbone type tensile specimens were used, (1 inch gage length standard, and 0.225 inch gage length mini), with laser and strain gage extensometers respectively. In addition, two different type of cross-weld tensile samples were prepared (full thickness with weld step, and milled to uniform thickness) in order to determine the effects of sample configuration on the measured properties. The results showed that the mini tensile samples can be used to estimate the stress-strain behavior of the full sized samples. However, the full thickness weld samples did not match the results from the milled cross-weld samples. The full thickness samples showed higher yield strengths than the milled samples due the strain localization in the region above 
the unwelded step, which incorporated a high fraction of weld material in it, even though the final failure occurred in the adjacent base metal. Measurements of the Young's modulus from the load displacement curve of the full thickness samples was shown to not be accurate due to the change in section thickness and sample bending, however, the laser extensometer on the standard size sample produced results much closer to the expected value than the strain gage extensometer on the mini sample.

While interpreting the tensile data, the following points should be kept in mind. Since the weld is harder and stronger than the annealed 21-6-9 SS base metal, all failures occur in the base metal regardless of tensile size or configuration, therefore, the standard size base metal sample provides the most accurate measure of the material behavior, largely due to the unlimited strain range of the laser extensometer that can be used on these samples. The elongation at failure varied from $47-62 \%$ in the standard sized samples with a 1 inch gage length. The measured $0.2 \%$ offset yield stress $(53.1 \pm 1.9 \mathrm{ksi})$, ultimate stress $(105.3 \pm 2.3 \mathrm{ksi})$ and Young's modulus (29.4 $\pm 0.95 \mathrm{Msi}$ ) values were largely independent of sample size or configuration, except for the full thickness cross-weld tensile where the yield stress was significantly higher $(73.4 \pm 3.9 \mathrm{ksi})$ due to the incorporation of stronger weld metal into the region and other factors such as sample bending and stress concentration at the step. The measured elongations at failure were highly reduced in the full thickness samples (10-28\%) as compared to the other sample configurations.

Spherical indentation testing using a nanoindenter was further performed on the 21-6-9 SS base metal and weld metal in a first attempt to generate a stress-strain curve for the electron beam welded metal. Using the base metal tensile tests to calibrate the nanoindenter, a Tabor factor of 3.6 was determined to produce the best fit of the 21-6-9 SS base metal indentation curve to the uniaxial tensile test data. This factor was then used to generate the stress strain curve for welded 21-6-9 SS from the nanoindentaion results, showing that the weld has a yield stress of $63.8 \mathrm{ksi}(440 \mathrm{MPa})$, which is approximately $25 \%$ higher than that of the base metal $50.8 \mathrm{ksi}(350 \mathrm{MPa})$. Note that the Steinberg-Guinan yield strength is less than the uniaxial experimental data since Steinberg-Guinan predicts an onset of yielding whereas the uniaxial tensile data uses a $0.2 \%$ offset to determine the yield strength. Further analysis showed that the strain hardening rate for the weld was approximately the same as that for the base metal. Uniaxial stress-strain models were fit to the quasi-static experimental data using both the Steinberg-Guinan and Johnson-Cook approaches, and the parameters for each model were determined for both the weld and base metals under quasi-static loading conditions as summarized in Table 5 and Table 6 . It is notable that the published Steinberg-Guinan data for 21-6-9 SS produces yield strengths significantly higher than what is measured in uniaxial tensile experimental data at quasi-static strain rates. This difference is related to the fact that the Steinberg-Guinan published data are optimized for high strain rates [13]. 
The relative yield strength of the weld to the base metal is an important consideration for welded joints. The results of the Steinberg-Guinan fits to the nanoindentation data under quasi-static strain rates indicate that the yield strength of the weld is $1.26 \mathrm{x}(63.8 \mathrm{ksi} / 50.8 \mathrm{ksi})$ higher than that of the annealed 21-6-9 SS base metal. Although the uniaxial tests were not able to confirm this ratio precisely due to the cross weld nature of the tensile samples, an estimate can be provided by taking the ratio of the measured yield stress for the base metal $\left(\sigma_{y}=53.1 \mathrm{ksi}\right)$ to that of the full thickness weld samples that contained a large fraction of weld metal in the high strain region $\left(\sigma_{y}=73.4 \mathrm{ksi}\right)$. This ratio $(73.4 \mathrm{ksi} / 53.1 \mathrm{ksi})$ of $1.38 \mathrm{x}$ is higher than the Steinberg-Guinan data derived ratio from the nanoindentaion tests. The difference is believed to be related to bending of the full thickness weld samples during uniaxial tensile testing, combined with stress concentrations in the highly strained region of the cross weld step joint samples. The true effects of the weld metal contributions to the stress strain behavior of a step welded joint will require finite element modeling of the step joint geometry as the next step in the analysis to take these other factors into account, and by incorporating the stress strain curves experimentally determined in this study for 21-6-9 SS base and weld metals.

\section{Acknowledgment and Auspices}

The authors would like to thank Gilbert Gallegos for supplying the 21-6-9 SS material, Mark Gauthier for performing the electron beam welding, and Jackson Go for assistance with the high magnification micrographs of the electron beam welds. This work performed under the auspices of the U.S. Department of Energy by Lawrence Livermore National Laboratory under Contract DE-AC52-07NA27344. This document was prepared as an account of work sponsored by an agency of the United States government. Neither the United States government nor Lawrence Livermore National Security, LLC, nor any of their employees makes any warranty, expressed or implied, or assumes any legal liability or responsibility for the accuracy, completeness, or usefulness of any information, apparatus, product, or process disclosed, or represents that its use would not infringe privately owned rights. Reference herein to any specific commercial product, process, or service by trade name, trademark, manufacturer, or otherwise does not necessarily constitute or imply its endorsement, recommendation, or favoring by the United States government or Lawrence Livermore National Security, LLC. The views and opinions of authors expressed herein do not necessarily state or reflect those of the United States government or Lawrence Livermore National Security, LLC, and shall not be used for advertising or product endorsement purposes. 


\section{References}

1. D. J. Alexander and C. T. Necker, "Characterization of Microstructures and Mechanical Properties of Current and Legacy 21-6-9 Stainless Steel Components" Los Alamos National Laboratory Report, LA-UR-11-02857, 2011.

2. M. E. Kassner and R. Breithaup, "The Yield Stress of Type 21-6-9 Stainless Steel Over a Wide range of Strain Rate $\left(10^{-5}\right.$ to $\left.10^{4} \mathrm{~s}^{-1}\right)$ and Temperature," LLNL Report, UCRL-89779, 1983.

3. J. W. Elmer and A. T. Teruya, "An Enhanced Faraday Cup for the Rapid Determination of the Power Density Distribution in Electron Beams," Welding Journal, 80 (12), p 288s, 2001.

4. J. W. Elmer, "Characterization of Defocused Electron Beams and Welds in Stainless Steel and Refractory Metals using the Enhanced Modified Faraday Cup Diagnostic," Lawrence Livermore National Laboratory Technical Report, TR-410752, February 17, 2009.

5. D. Hiromoto, "Stainless Steel Weld Studies," LLNL report ERD11-500089-AA, July 27, 2011.

6. J. W. Elmer, S. M. Allen, and T. W. Eagar, "Microstructural Development During Solidification Of Stainless Steel Alloys," Metall. Trans. A, 20A (10), p 2117, 1989.

7. Aerospace Structural Materials Handbook, Vol 1 Ferrous Alloys, Battelle Columbus Division, 1987.

8. Handbook of Stainless Steels, Peckner and Bernstein, MGraw Hill, 1977.

9. C. Hills and H. Rack, "Effects of shock Deformation on the Residual Strength and Microstructure of Nitronic 40 Stainless Steel," Mat. Sci. and Eng., 51, p. 231, 1981.

10. The Harndess of Metals, D. Tabor, 1951.

11. S.R. Kalidindi and S. Pathak, "Determination of the Effective Zero-Point and the Extraction of Spherical Nanoindentation Stress-Strain Curves," Acta Met., V56, p3523, 2008.

12. D. J. Steinberg et al, "A Constitutive Model for Metals Applicable at High Strain Rates," JAP, 51, p1499, 1980.

13. D. J. Steinberg, Equation of State and Strength Properties of Selected Materials, UCRL-MA106439, February 13, 1991.

14. M. Tang, P. Norquist, N. Barton, K. Durrenberger J. Florando, A. Attia, MIDAS (Material Implementation, Database, and Analysis Source), LLNL-PROC-464065, December 2010.

15. G.R. Johnson and W.H. Cook, "A Constitutive Model and Data for Metals Subjected to Large Strains, High Strain Rates, and High Temperatures," Proceedings of the $7^{\text {th }}$ International Symposium on Ballistics, The Hague, Netherlands, p 541, 1983. 
Table 1: 21-6-9 stainless steel alloy composition compared to nominal and LLNL aim ranges.

\begin{tabular}{|c|c|c|c|c|}
\hline Element & $\begin{array}{c}\text { Actual } \\
(w t \%)\end{array}$ & $\begin{array}{c}\text { Specification } \\
(w t \%)\end{array}$ & $\begin{array}{c}\text { LLNL Guarantee } \\
(w t \%)\end{array}$ & $\begin{array}{c}\text { LLNL Aim } \\
\text { (wt\%) }\end{array}$ \\
\hline Carbon & 0.02 & 0.08 Max & $0.02-0.04$ & 0.04 max \\
\hline Chromium & 19.96 & $19.0-21.5$ & $19.0-21.5$ & $20-20.5$ \\
\hline Nickel & 7.02 & $5.5-7.5$ & $5.5-7.5$ & $6.0-6.5$ \\
\hline Manganese & 9.14 & $8.0-10.0$ & $8.0-10.0$ & $8.5-9.5$ \\
\hline Silicon & 0.05 & 1.0 Max & $0.3-0.7$ & 0.50 max \\
\hline Nitrogen & 0.23 & $0.15-0.40$ & $0.20-0.30$ & $0.23-0.25$ \\
\hline Phosphorous & 0.014 & 0.06 Max & 0.020 Max & 0.000 \\
\hline Sulfur & $<0.005$ & 0.03 Max & 0.02 Max & 0.000 \\
\hline Oxygen & $<0.001$ & ---- & 0.007 Max & $0.000-0.005$ \\
\hline Iron & Balance & Balance & Balance & Balance \\
\hline
\end{tabular}

Table 2: Summary of the electron beam properties for each of the six welds along with the resulting weld depths and widths across the top surface of the plate.

\begin{tabular}{|c|c|c|c|c|c|c|}
\hline Weld & $\begin{array}{c}\text { Focus } \\
\text { Setting } \\
(\mathrm{mA})\end{array}$ & $\begin{array}{c}\text { Peak PD } \\
\left(\mathrm{W} / \mathrm{mm}^{2}\right)\end{array}$ & $\begin{array}{c}\text { FWHM } \\
(\mathrm{mm})\end{array}$ & $\begin{array}{c}\text { Diameter } \\
(\mathrm{mm})\end{array}$ & $\begin{array}{c}\text { Weld } \\
\text { Depth } \\
(\mathrm{mm})\end{array}$ & $\begin{array}{c}\text { Weld Width } \\
(\mathrm{mm})\end{array}$ \\
\hline 1 & $762(+32)$ & 1500 & 0.49 & 0.98 & 0.98 & 1.53 \\
\hline 2 & $760(+30)$ & 1550 & 0.51 & 0.97 & 1.03 & 1.52 \\
\hline 3 & $760(+30)$ & 1510 & 0.51 & 0.98 & 1.11 & 1.56 \\
\hline 4 & $759(+29)$ & 1480 & 0.54 & 1.00 & 1.14 & 1.55 \\
\hline 5 & $759(+29)$ & 1445 & 0.52 & 1.01 & 1.00 & 1.53 \\
\hline 6 & $759(+29)$ & 1470 & 0.51 & 0.99 & 0.99 & 1.51 \\
\hline Avg. / STD & $759.8 / 1.2$ & $1493 / 36.2$ & $0.51 / .02$ & $0.99 / .02$ & $1.04 / .07$ & $1.53 / .02$ \\
\hline
\end{tabular}


Table 3: Vickers microhardness measurements (50 gm load) made on the 21-6-9 base metal, weld $\mathrm{HAZ}$, and weld fusion zone.

\begin{tabular}{|c|c|c|c|}
\hline Weld & $\begin{array}{c}\text { Base Metal Hardness } \\
\text { Avg/STD }(\mathrm{HV})\end{array}$ & $\begin{array}{c}\text { HAZ Hardness } \\
\text { Avg/STD }(\mathrm{HV})\end{array}$ & $\begin{array}{c}\text { Weld Metal Hardness } \\
\text { Avg/STD }(\mathrm{HV})\end{array}$ \\
\hline 1 & $215.8 / 11.2$ & $226.8 / 10.4$ & $258.9 / 10.0$ \\
\hline 2 & $212.5 / 6.50$ & $241.1 / 14.3$ & $257.8 / 9.60$ \\
\hline 3 & $216.0 / 6.60$ & $225.8 / 8.30$ & $249.6 / 10.1$ \\
\hline 4 & $209.5 / 10.0$ & $226.7 / 10.1$ & $258.2 / 10.9$ \\
\hline 5 & $201.0 / 7.70$ & $235.5 / 18.0$ & $247.2 / 13.2$ \\
\hline 6 & $218.3 / 7.50$ & $237.4 / 12.1$ & $254.9 / 6.60$ \\
\hline Avg. / STD & $212.1 / 10.9$ & $232.1 / 13.9$ & $254.4 / 9.7$ \\
\hline Number of Points & 36 & 49 & 62 \\
\hline
\end{tabular}


Table 4: Summary of the tensile test results on the parent metal, milled cross-weld tensile samples, and full-thickness tensile samples. All samples tested at room temperature.

\begin{tabular}{|c|c|c|c|c|c|c|c|c|c|c|}
\hline Specimen ID & Condition & Size & Width & Thick & Area & Ext. GL & Xhd & $\begin{array}{l}\text { Young's } \\
\text { Moduls }\end{array}$ & $\begin{array}{c}\text { Yield } \\
\text { Strength } \\
0.2 \% \text { offset }\end{array}$ & $\begin{array}{c}\text { Ultimate } \\
\text { Tensile } \\
\text { Strength }\end{array}$ \\
\hline & & & (in) & (in) & $\left(\mathrm{in}^{2}\right)$ & (in) & (in/min) & (Msi) & (ksi) & (ksi) \\
\hline P_Tab2_1 & Parent & Mini & 0.1011 & 0.0303 & 0.0030 & 0.225 & 0.02 & 30.7 & $64.0 *$ & 105.2 \\
\hline P_Tab2_2 & Parent & Mini & 0.1009 & 0.0302 & 0.0030 & 0.225 & 0.02 & 29.0 & 50.0 & 103.1 \\
\hline P_Tab2_3 & Parent & Mini & 0.101 & 0.0297 & 0.0030 & 0.225 & 0.02 & 28.6 & 50.2 & 104.4 \\
\hline P_Tab1_1 & Parent & Std. & 0.2492 & 0.0303 & 0.0075 & 1.071 & 0.05 & 30.7 & 53.0 & 104.3 \\
\hline P_Tab1_2 & Parent & Std. & 0.2491 & 0.0299 & 0.0074 & 1.0928 & 0.05 & 30.7 & 52.0 & 103.4 \\
\hline P_Tab1_3 & Parent & Std. & 0.2491 & 0.0290 & 0.0072 & 1.0938 & 0.05 & 29.6 & 52.8 & 101.6 \\
\hline W_Tab2_Plate1_1 & Weld, milled & Mini & 0.1007 & 0.0299 & 0.0030 & 0.225 & 0.02 & 28.0 & 55.7 & 105.5 \\
\hline W_Tab2_Plate1_2 & Weld, milled & Mini & 0.1007 & 0.0303 & 0.0030 & 0.225 & 0.02 & 28.6 & 55.5 & 105.8 \\
\hline W_Tab2_Plate1_3 & Weld, milled & Mini & 0.1003 & 0.0303 & 0.0030 & 0.225 & 0.02 & 29.6 & 54.4 & 105.1 \\
\hline W_Tab1_Plate1_1 & Weld, milled & Std. & 0.2492 & 0.0306 & 0.0076 & 1.0834 & 0.05 & 28.6 & 53.5 & 104.4 \\
\hline W_Tab1_Plate1_2 & Weld, milled & Std. & 0.2493 & 0.0301 & 0.0075 & 1.0912 & 0.05 & 28.6 & 52.8 & 103.9 \\
\hline W_Tab1_Plate1_3 & Weld, milled & Std. & 0.2492 & 0.0302 & 0.0075 & 1.0892 & 0.05 & 29.6 & 54.0 & 105.1 \\
\hline Fweld_Tab2_Plate2_2 & Weld, full & Mini & 0.0998 & 0.0383 & 0.0038 & 0.1394 & 0.02 & $21.8^{* *}$ & 67.0 & 102.3 \\
\hline Fweld_Tab2_Plate2_3 & Weld, full & Mini & 0.0998 & 0.0355 & 0.0035 & 0.1381 & 0.02 & $18.5^{* *}$ & 70.0 & 110.2 \\
\hline Fweld_Tab2_Plate2_4 & Weld, full & Mini & 0.0998 & 0.0373 & 0.0037 & 0.107 & 0.02 & $18.5^{* *}$ & 75.5 & 108.3 \\
\hline Fweld_Tab1_Plate2_1 & Weld, full & Std. & 0.2488 & 0.0380 & 0.0094 & 1.081 & 0.05 & $30 * *$ & 76.0 & 108.1 \\
\hline Fweld_Tab1_Plate2_2 & Weld, full & Std. & 0.249 & 0.0358 & 0.0089 & 1.069 & 0.05 & $30 * *$ & 76.0 & 107.2 \\
\hline Fweld_Tab1_Plate 2 & Weld, full & Std. & 0.2481 & 0.0370 & 0.0091 & 1.0638 & 0.05 & $30 * *$ & 76.0 & 107.3 \\
\hline
\end{tabular}

*Sample unintentionally prestrained prior to testing, creating erroneous high yield strength **Young's modulus data not accurate due to the change in sample thickness and sample bending 
Table 5: Recommended Steinberg-Guinan parameters for the 21-6-9 SS experimental weld metal and annealed base metal values under quasi-static strain rate conditions, compared to the published base metal value at high strain rates.

\begin{tabular}{|c|c|c|c|c|}
\hline $\begin{array}{c}\text { Steinberg- } \\
\text { Guinan } \\
\text { Parameter }\end{array}$ & Definition & $\begin{array}{c}\text { Base Metal } \\
\text { Published Value } \\
{[13]} \\
\text { (high rate) }\end{array}$ & $\begin{array}{c}\text { Base Metal } \\
\text { Experimental } \\
\text { Value } \\
\text { (quasi-static) }\end{array}$ & $\begin{array}{c}\text { Weld Metal } \\
\text { Value } \\
\text { (quasi-static) }\end{array}$ \\
\hline $\mathrm{Y}_{\mathrm{o}}$ & Yield Stress & $\begin{array}{c}0.0068 \mathrm{Mbar} \\
(680 \mathrm{MPa})\end{array}$ & $\begin{array}{c}0.0035 \mathrm{Mbar} \\
(350 \mathrm{MPa})\end{array}$ & $\begin{array}{c}0.0044 \mathrm{Mbar} \\
(440 \mathrm{MPa})\end{array}$ \\
\hline$\beta$ & $\begin{array}{c}\text { Hardening } \\
\text { Coefficient }\end{array}$ & 35 & 20 & 33 \\
\hline $\mathrm{n}$ & $\begin{array}{c}\text { Hardening } \\
\text { Exponent }\end{array}$ & 0.23 & 0.5 & 0.375 \\
\hline $\mathrm{Y}_{\max }$ & $\begin{array}{c}\text { Saturation } \\
\text { Stress }\end{array}$ & $\begin{array}{c}0.025 \\
(2.5 \mathrm{GPa})\end{array}$ & $\begin{array}{c}0.025 \\
(2.5 \mathrm{GPa})\end{array}$ & $\begin{array}{c}0.025 \\
(2.5 \mathrm{GPa})\end{array}$ \\
\hline
\end{tabular}

Table 6: Recommended Johnson-Cook strength parameters for the 21-6-9 SS weld metal and annealed base metal, under quasi-static strain rate conditions.

\begin{tabular}{|c|c|c|c|}
\hline $\begin{array}{c}\text { Johnson- Cook } \\
\text { Parameter }\end{array}$ & Definition & $\begin{array}{c}\text { Base Metal Value } \\
\text { (quasi-static) }\end{array}$ & $\begin{array}{c}\text { Weld Metal Value } \\
\text { (quasi-static) }\end{array}$ \\
\hline $\mathrm{A}$ & $\begin{array}{c}\text { Effective Yield Stress } \\
\text { at } \dot{\varepsilon}_{o}=1 / \mathrm{s} \text { and T=RT }\end{array}$ & $\begin{array}{c}0.0055 \mathrm{Mbar} \\
(550 \mathrm{MPa})\end{array}$ & $\begin{array}{c}0.0078 \mathrm{Mbar} \\
(780 \mathrm{MPa})\end{array}$ \\
\hline $\mathrm{B}$ & $\begin{array}{c}\text { Hardening } \\
\text { Coefficient }\end{array}$ & $\begin{array}{c}0.0024 \mathrm{Mbar} \\
(240 \mathrm{MPa})\end{array}$ & $\begin{array}{c}0.0024 \mathrm{Mbar} \\
(240 \mathrm{MPa})\end{array}$ \\
\hline $\mathrm{n}$ & $\begin{array}{c}\text { Hardening } \\
\text { Exponent }\end{array}$ & 0.65 & 0.65 \\
\hline $\mathrm{C}$ & Strain Rate Coefficient & 0.044 & 1.0 \\
\hline $\mathrm{m}$ & Temperature Exponent & 1.0 & $2380 \mathrm{~K}$ \\
\hline $\mathrm{T}_{\mathrm{melt}}$ & Melting Temperature & $2380 \mathrm{~K}$ & $295 \mathrm{~K}$ \\
\hline $\mathrm{T}_{\text {room }}$ & $\begin{array}{c}\text { Ambient Room } \\
\text { Temperature }\end{array}$ & $295 \mathrm{~K}$ & $1 / \mathrm{s}$ \\
\hline$\dot{\varepsilon}_{o}$ & Reference Strain Rate & $1 / \mathrm{s}$ & 0.044 \\
\hline
\end{tabular}



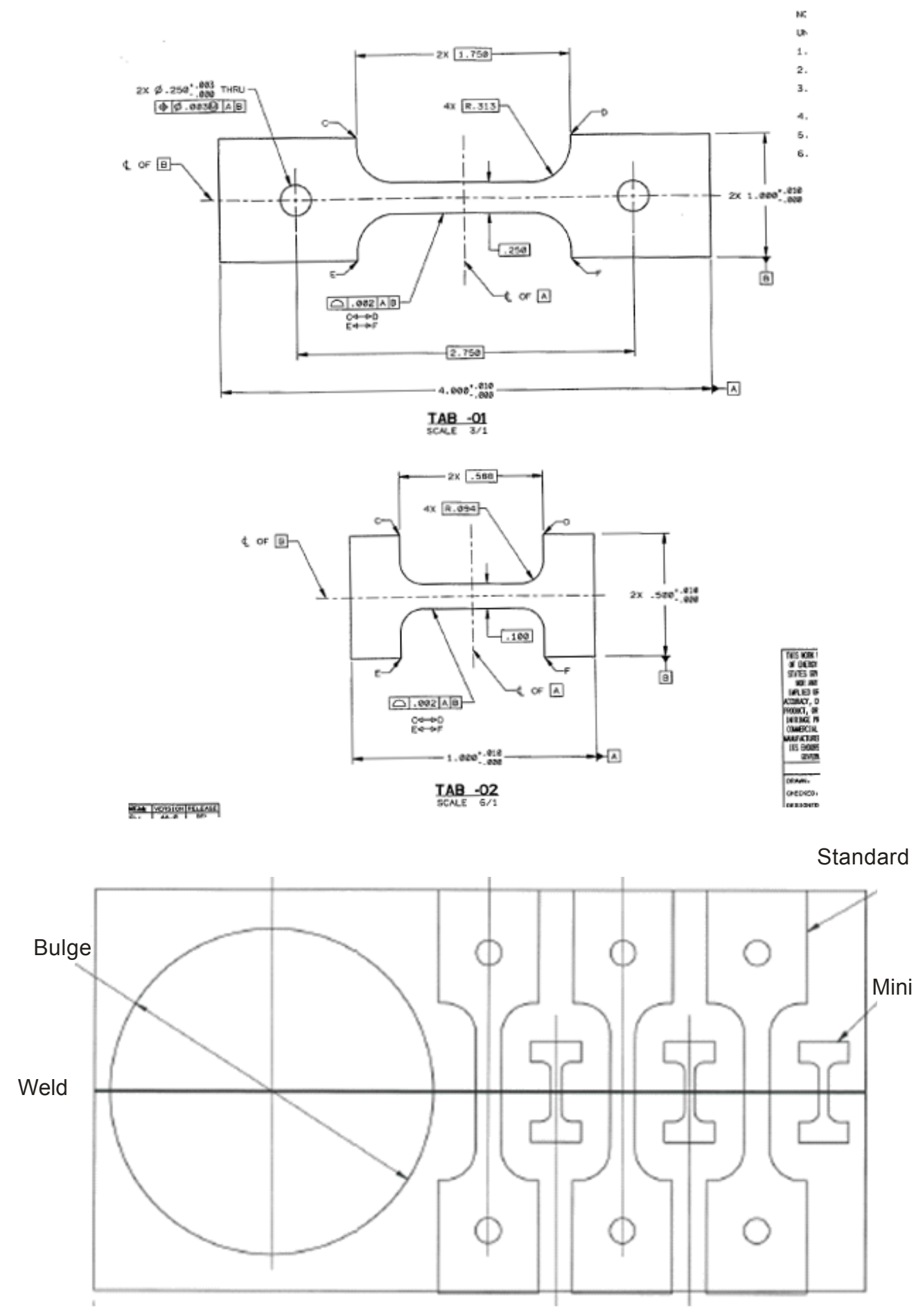

Figure 1: a) Drawings of the standard size (Tab-01) and mini (Tab-02) tensile bars with dimensions in inches, and b) layout of the 3 mini tensile coupons, 3 standard tensile coupons, and one bulge coupon per $4 \times 8$ inch welded plate. 


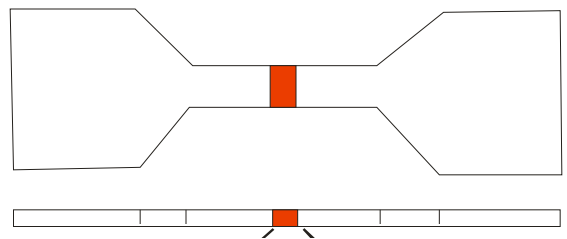

(a)

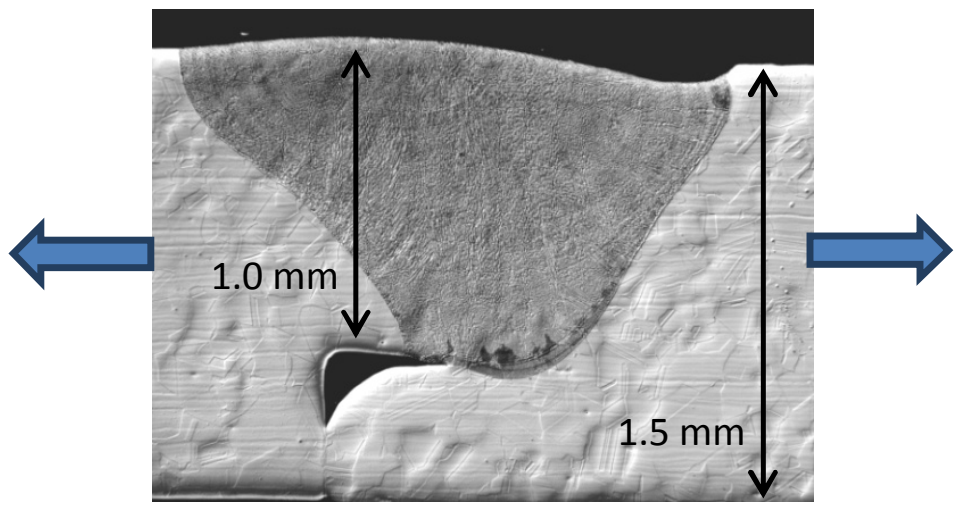

(b)

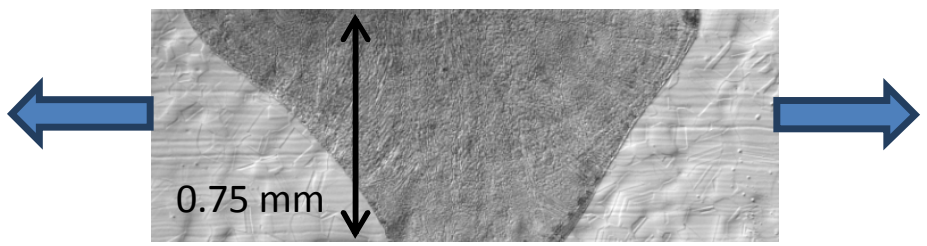

(c)

Figure 2: a) Illustration of the top and side views of cross-weld tensile bar, where the red shading indicates the weld location. b) micrograph of the full thickness type 1 weld coupon with step-joint related change in section thickness, c) cropped photo illustrating cross section of the type 2 weld coupon after machining to remove the unwelded material below the step, the weld reinforcement, and the weld undercut. The large arrows indicate the tensile axis direction relative to the weld. 
Defocused +45 for $605 \mathrm{~W}$ beam:

Beam Diameter $\left(1 / \mathrm{e}^{2}\right)=1.17 \mathrm{~mm}$

$\mathrm{FWHW}=0.65 \mathrm{~mm}$

Peak PD $=1.12 \mathrm{~kW} / \mathrm{mm}^{2}$

Avg. PD $=0.553 \mathrm{~kW} / \mathrm{mm}$

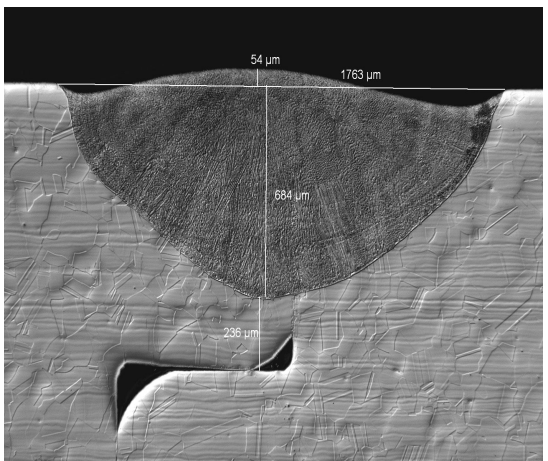

Defocused +40 for $605 \mathrm{~W}$ beam:

Beam Diameter $\left(1 / \mathrm{e}^{2}\right)=1.05 \mathrm{~mm}$

$\mathrm{FWHW}=0.59 \mathrm{~mm}$

Peak PD $=1.35 \mathrm{~kW} / \mathrm{mm}^{2}$

Avg. $P D=0.712 \mathrm{~kW} / \mathrm{mm}$

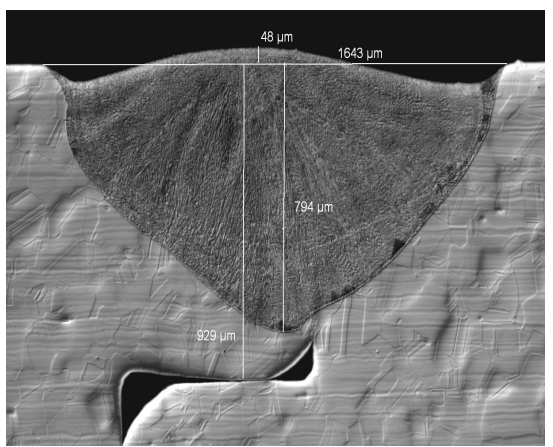

Defocused +35 for $605 \mathrm{~W}$ beam:

Beam Diameter $\left(1 / \mathrm{e}^{2}\right)=0.91 \mathrm{~mm}$

$\mathrm{FWHW}=0.51 \mathrm{~mm}$

Peak PD $=1.83 \mathrm{~kW} / \mathrm{mm}^{2}$

Avg. PD $=0.910 \mathrm{~kW} / \mathrm{mm}^{2}$

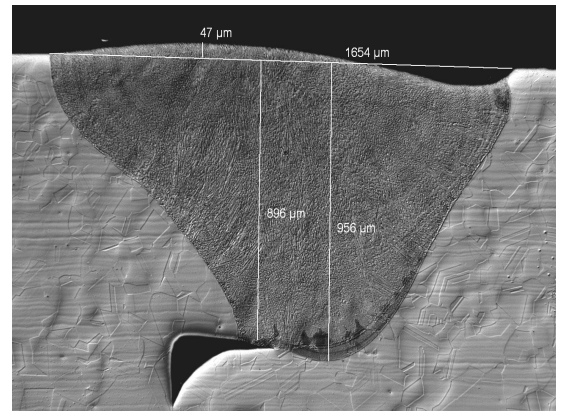

Figure 3: EMFC diagnostic measurements and weld cross sections for the first set of coupon welds, showing the difference in weld pool shape for 35,40 , and $45 \mathrm{~mm}$ defocus settings. 


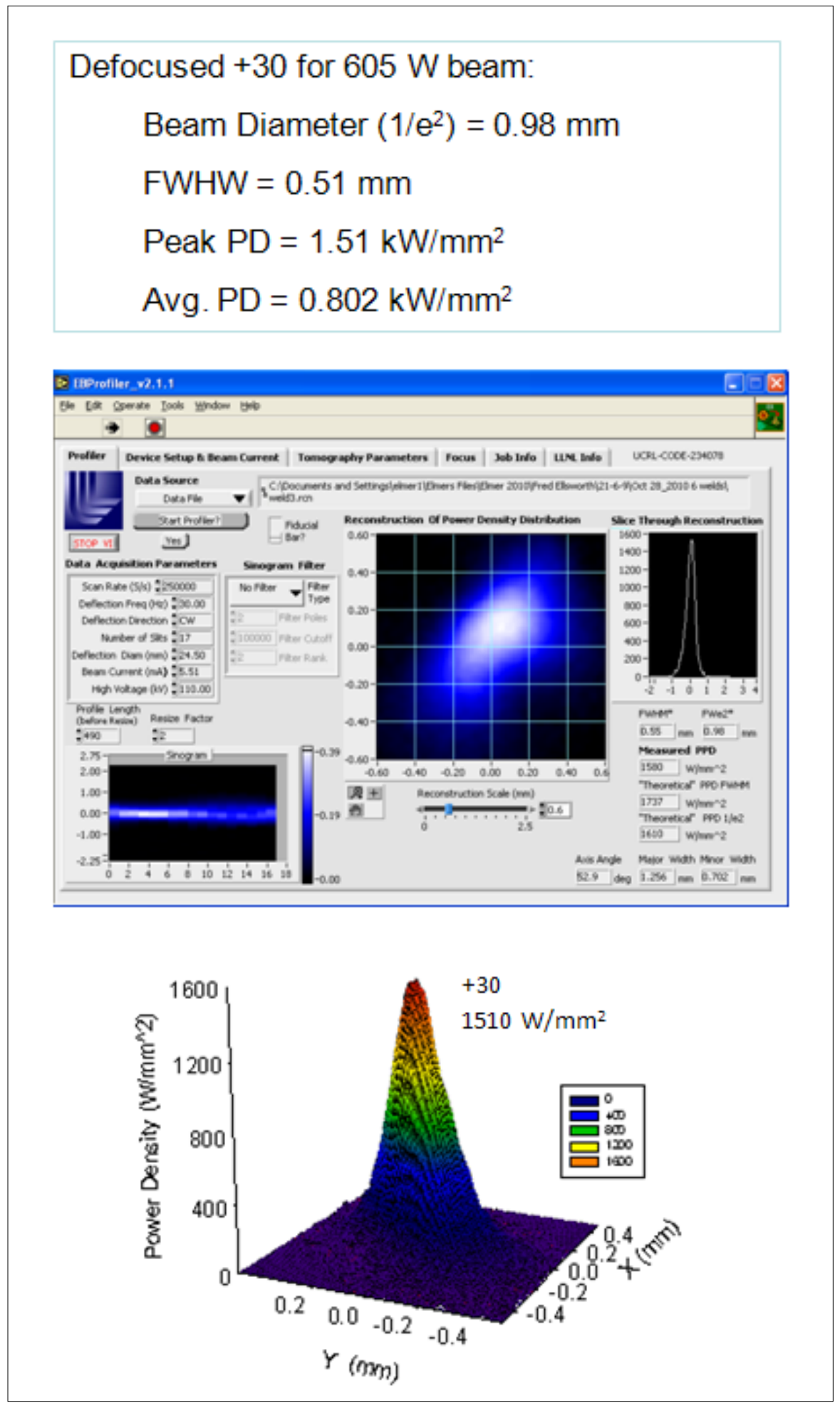

Figure 4: Results of the electron beam diagnostics for weld 3 (see Fig.5): a) the beam diagnostic summary, b) the overall diagnostic results, and c) a surface plot of the beam power density distribution. 


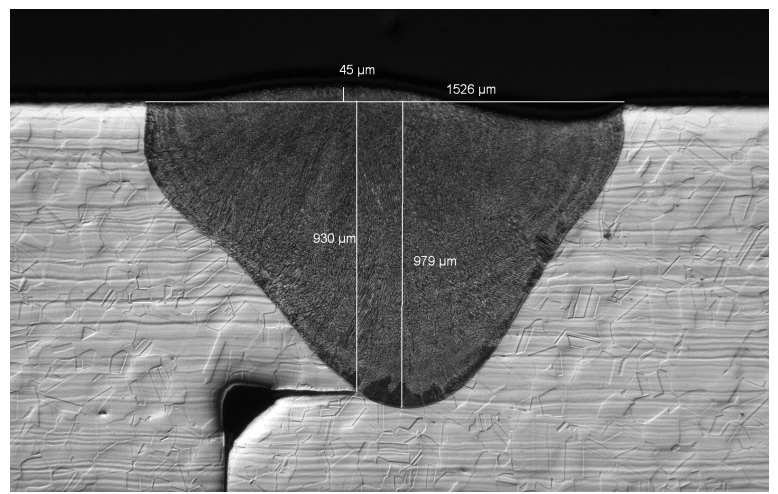

Weld \#1

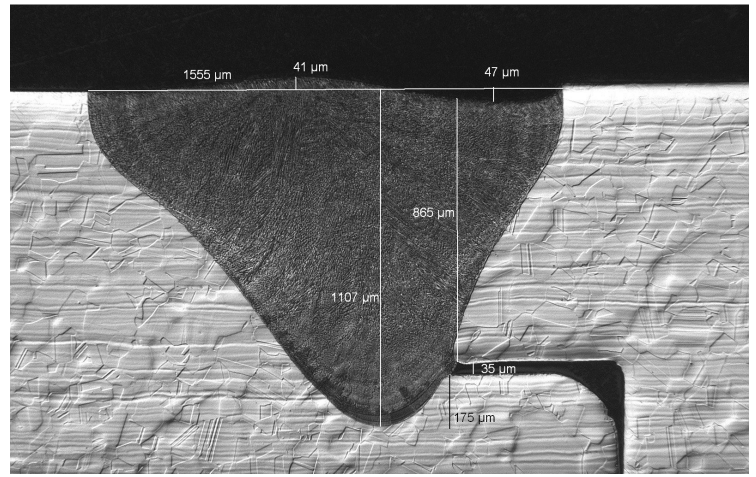

Weld \#3

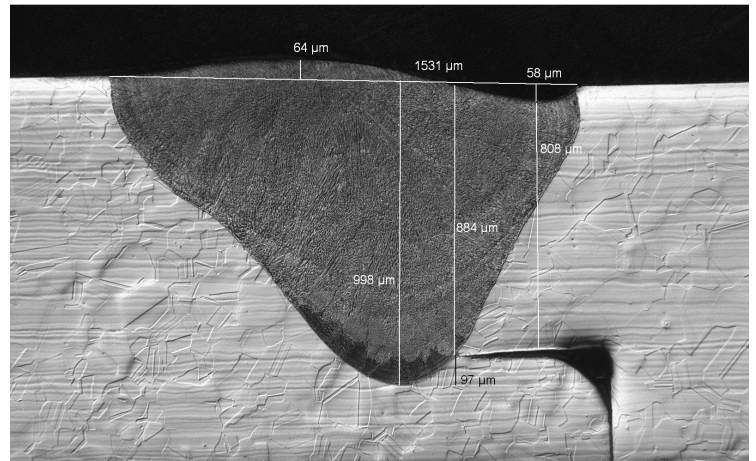

Weld \#5

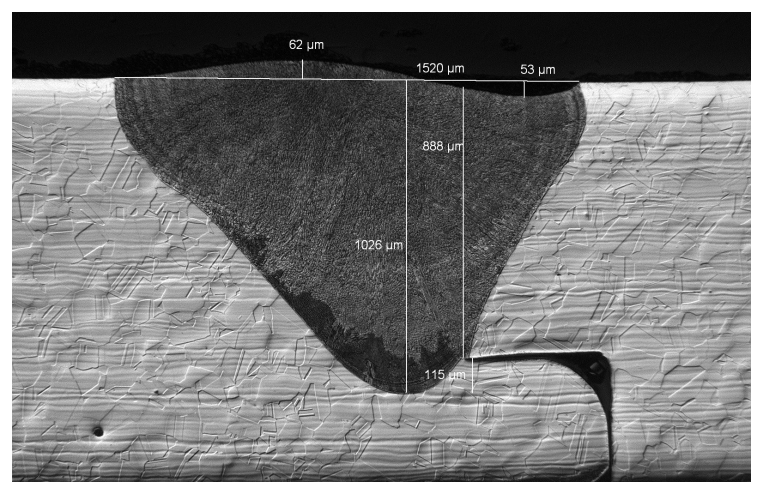

Weld \#2

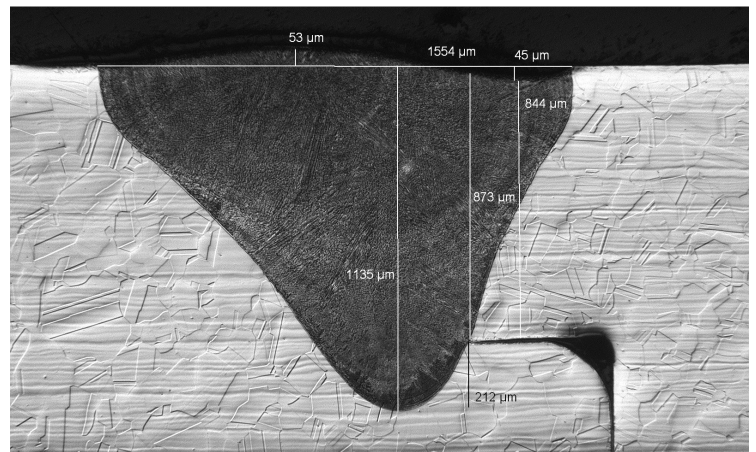

Weld \#4

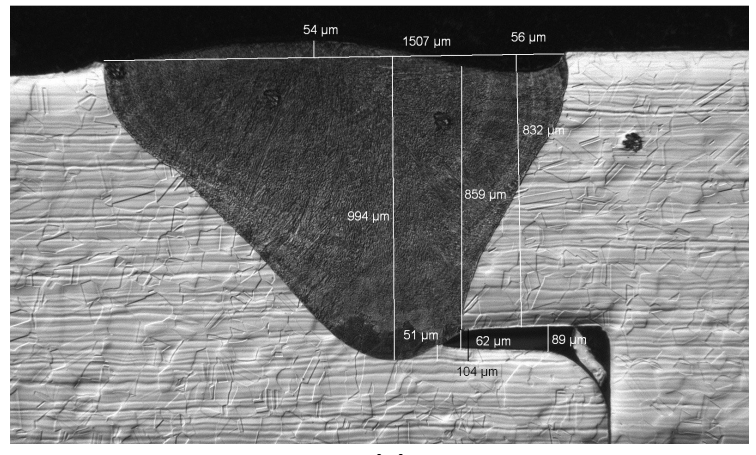

Weld \#6

Figure 5: Micrographs of each of the six electron beam welds made on 21-6-9 SS flat plates for preparation of mechanical testing specimens. Electron beam diagnostic results and weld statistics are summarized in Table 2 for each of the welds. 

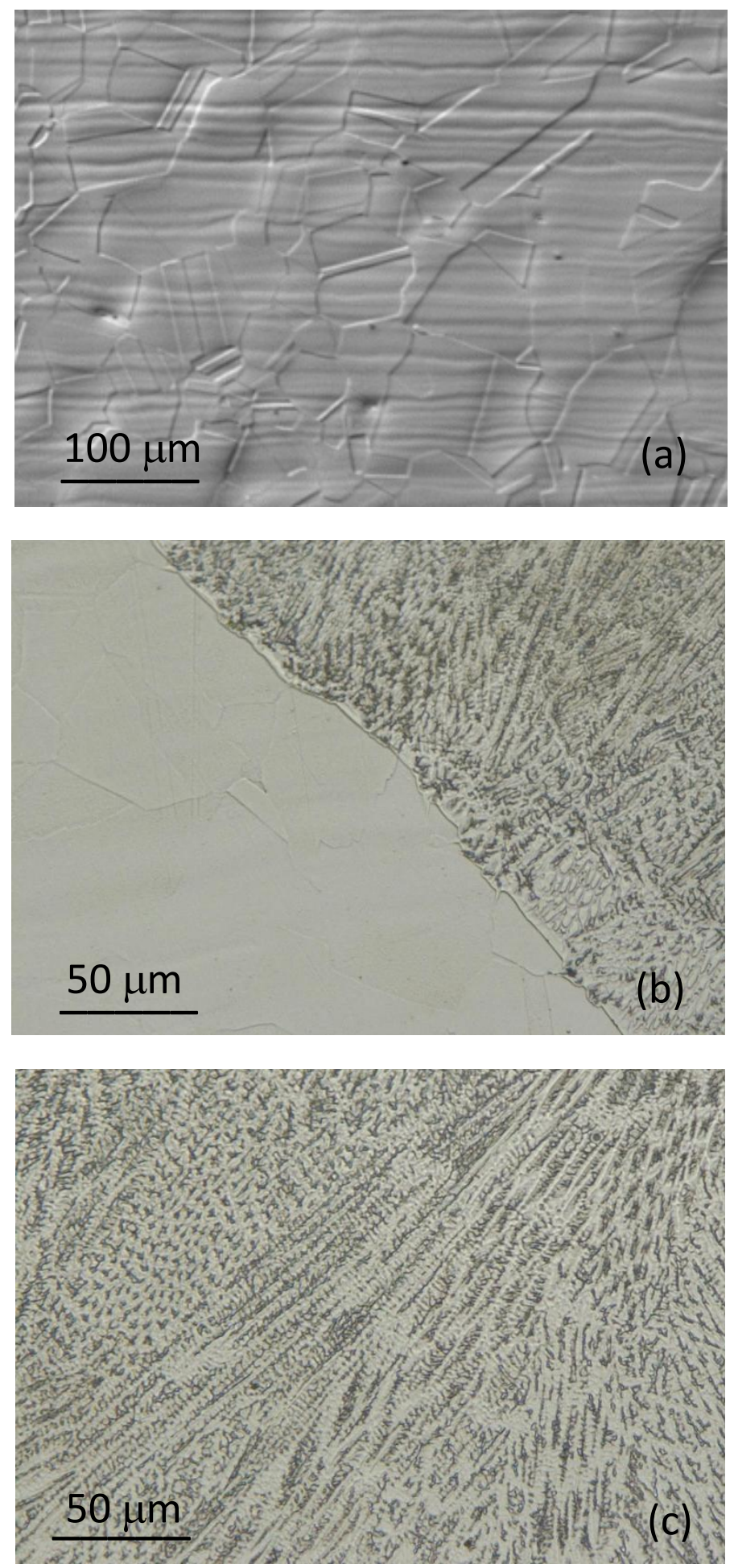

Figure 6: High magnification photomicrographs of: a) the base metal with a grain size of approximately $50 \mu \mathrm{m}, \mathrm{b}$ ) the fusion boundary of weld, and c) the central portion of the fusion zone showing the cellular/dendritic microstructure with a primary spacing of approximately $5 \mu \mathrm{m}$. 


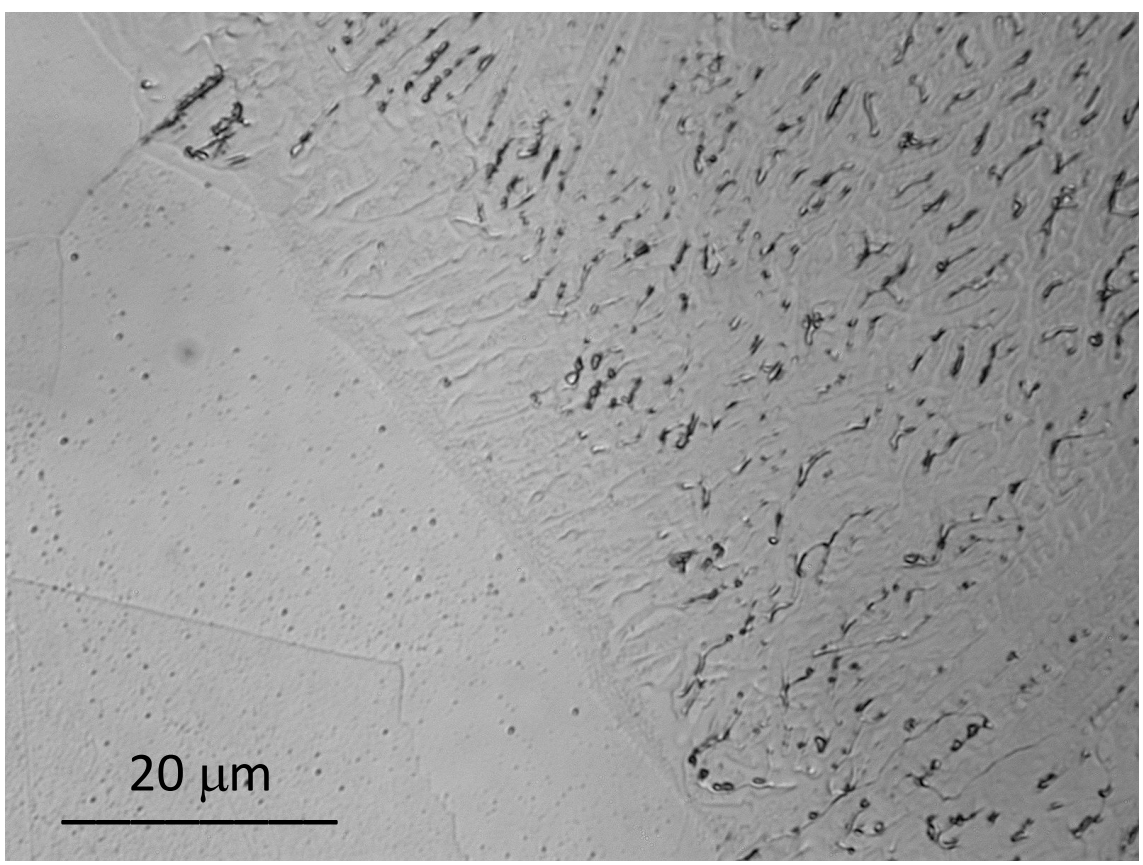

(a)

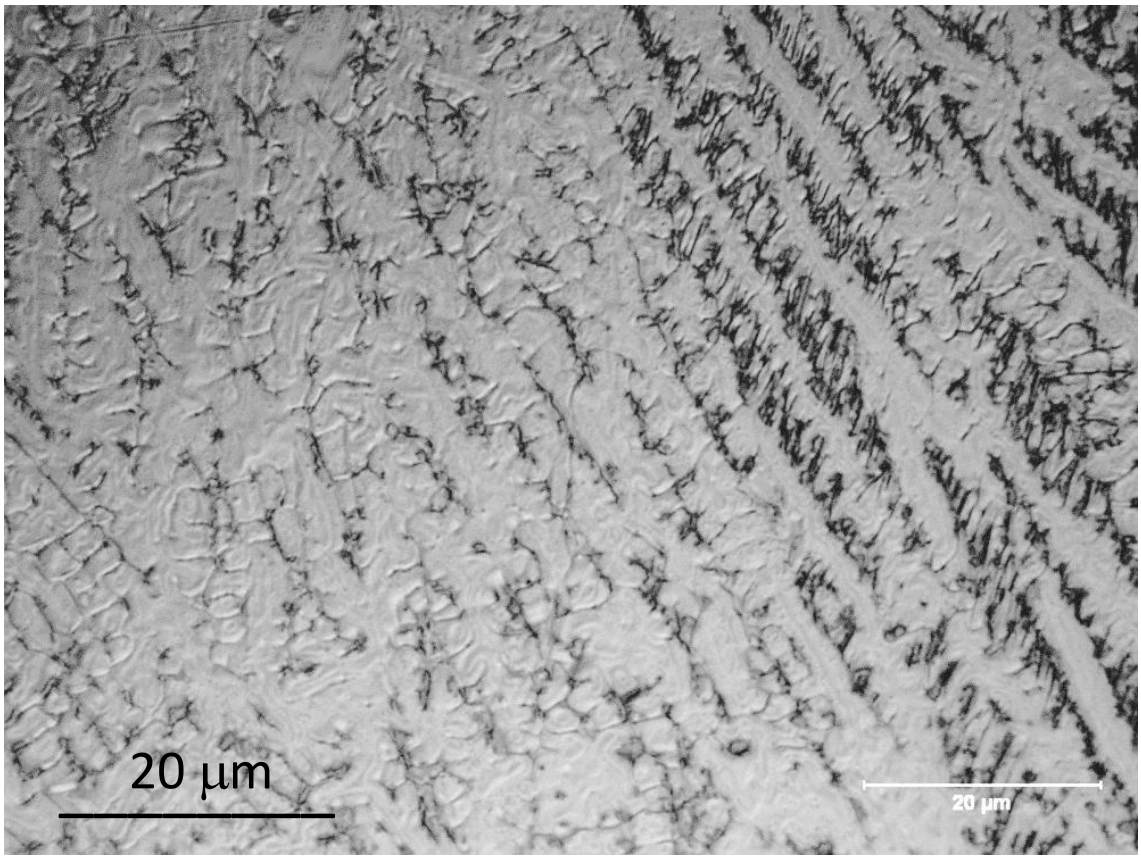

(b)

Figure 7: High magnification micrograph a) the fusion line of the weld, and b) the center section of the fusion zone. The dark etching phase is residual delta ferrite. Both photos shot at $1000 x$. 


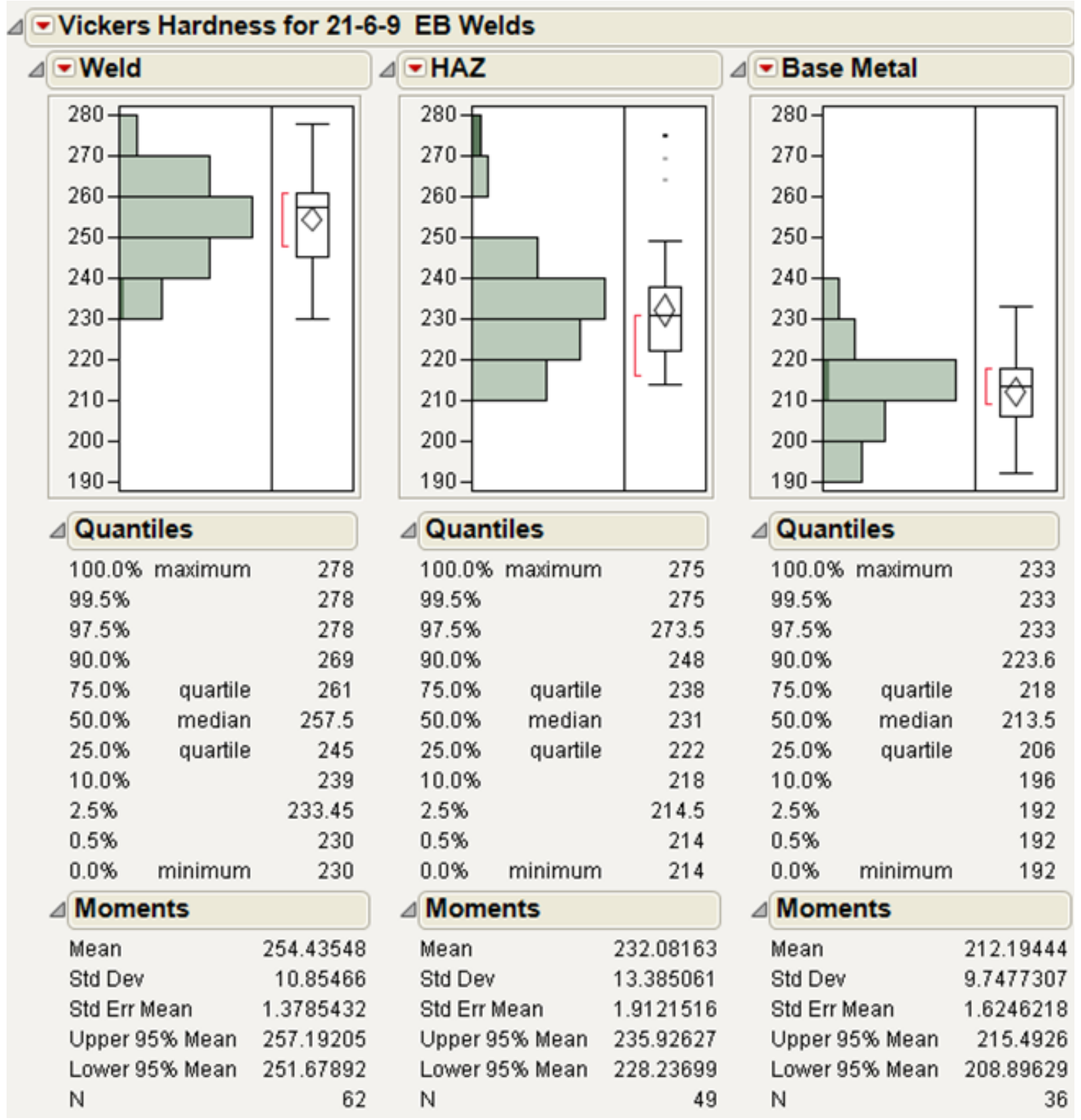

Figure 8: Statistical summary of the hardness measurements made on the six welded plates for the base metal, HAZ and weld fusion zone. 
Mini Samples

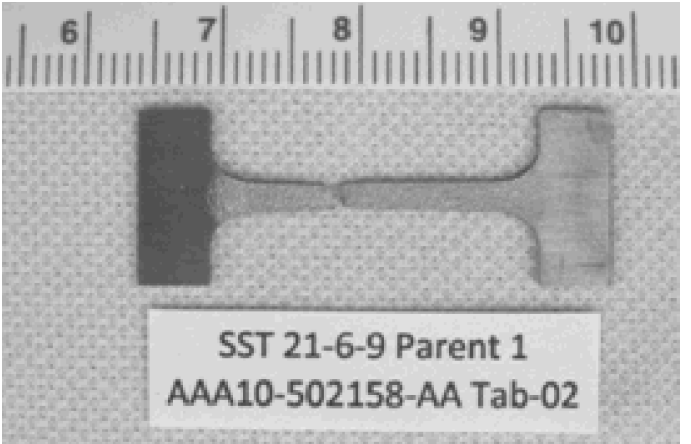

(a)

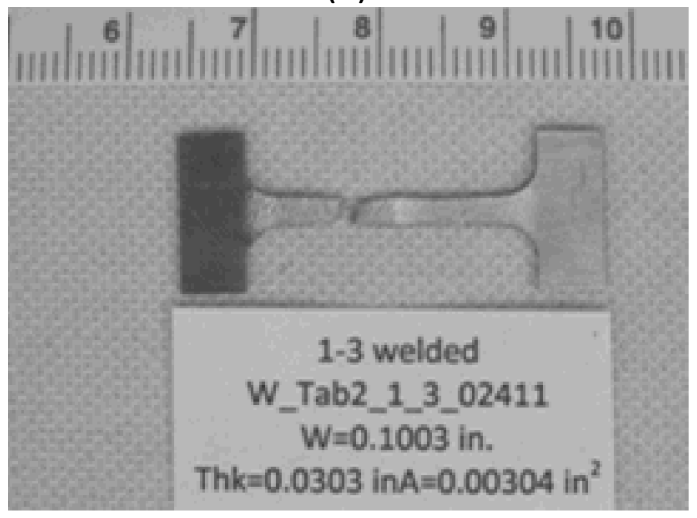

(b)

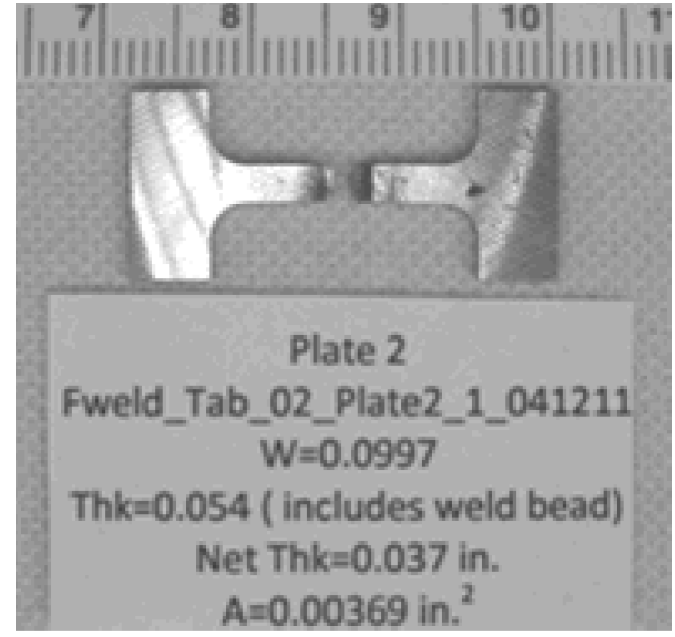

(c)

\section{Standard Samples}

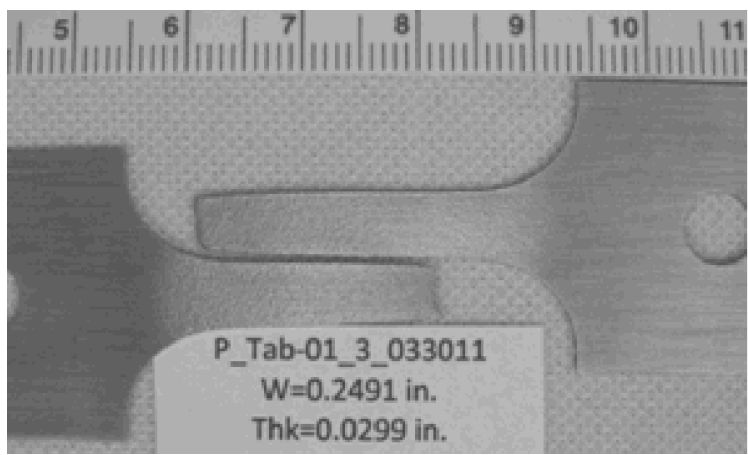

(d)

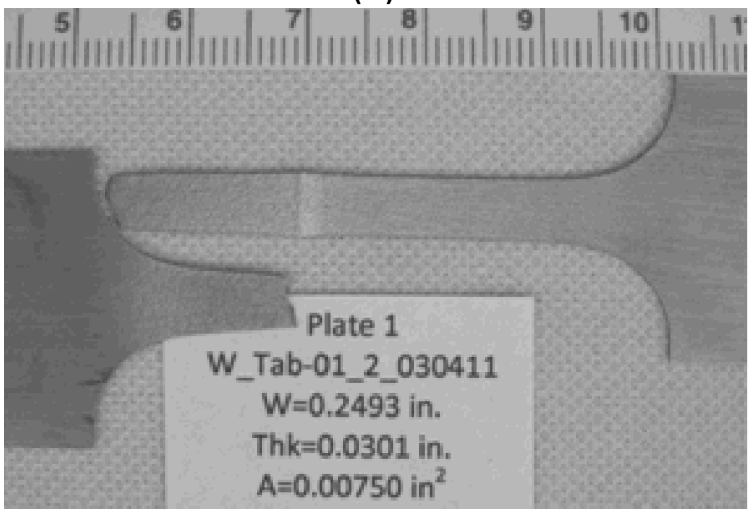

(e)

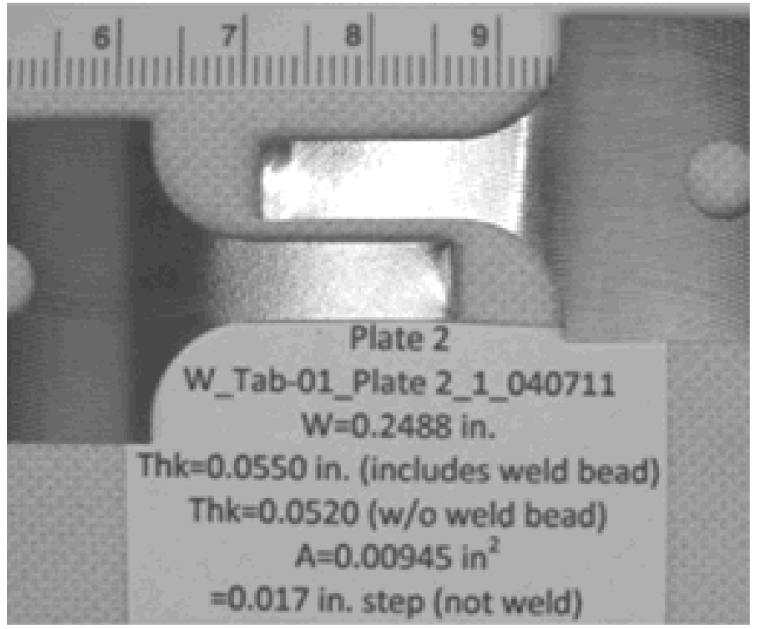

(f)

Figure 9: Photographs of representative tensile bars for each of the six different configurations. The small divisions in the scale markers in the photographs are $1 \mathrm{~mm}$ increments. 


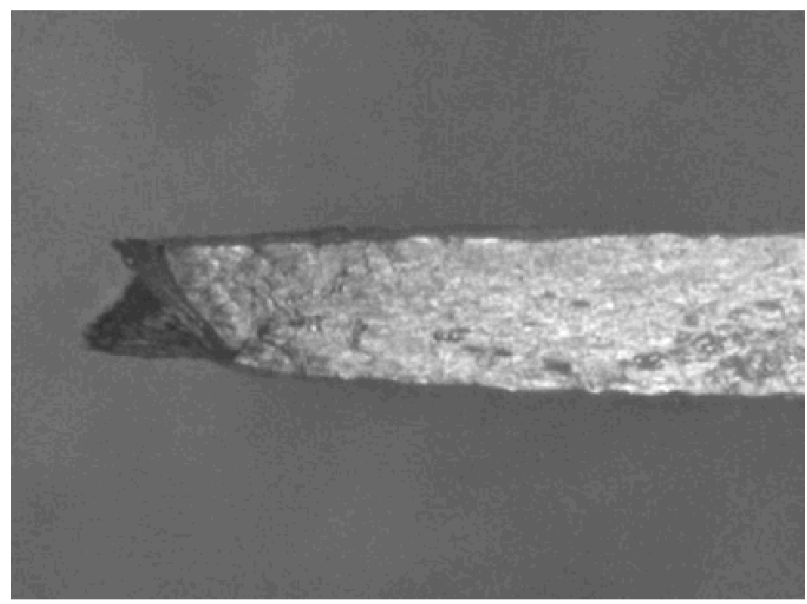

(a)

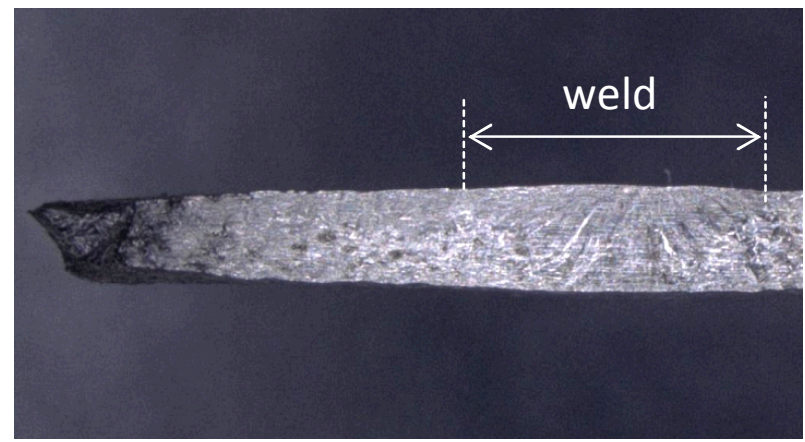

(c)

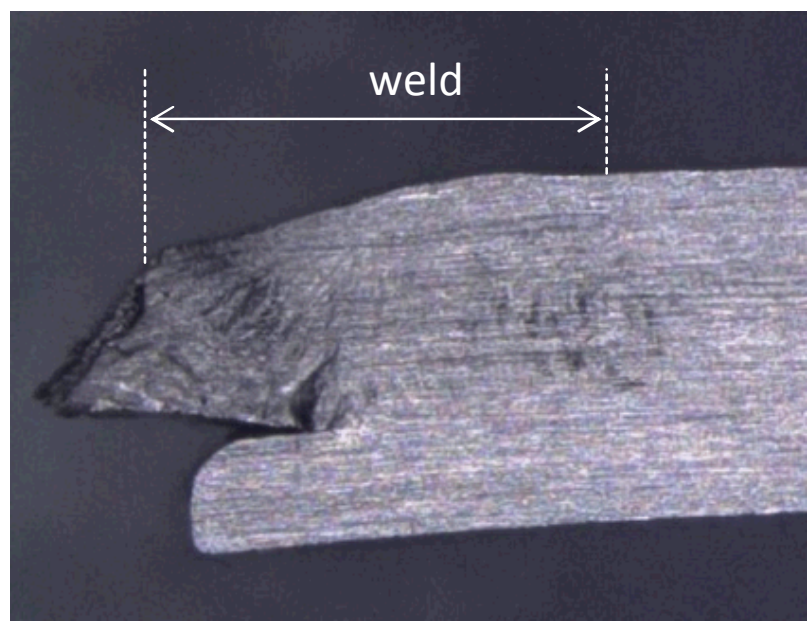

(e)

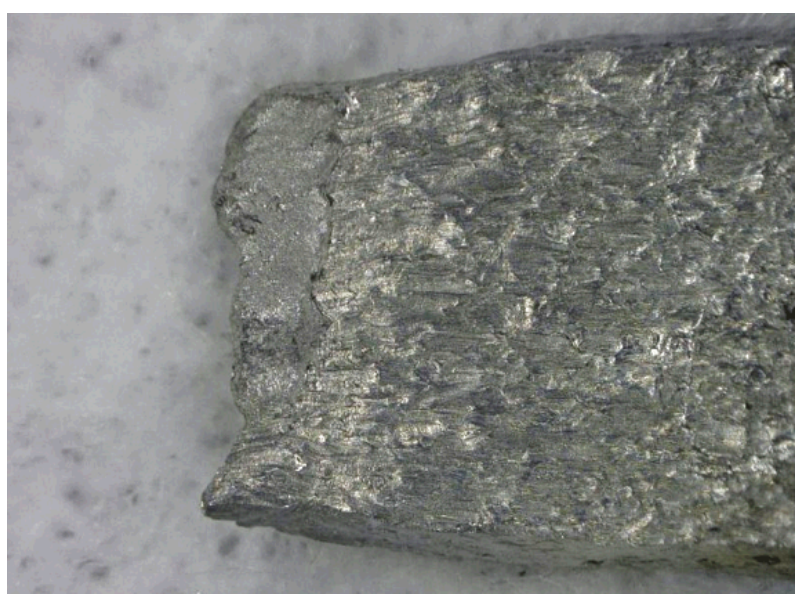

(b)

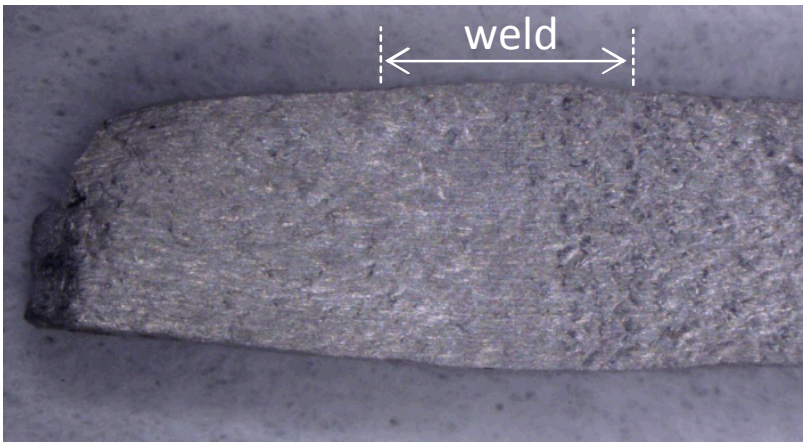

(d)

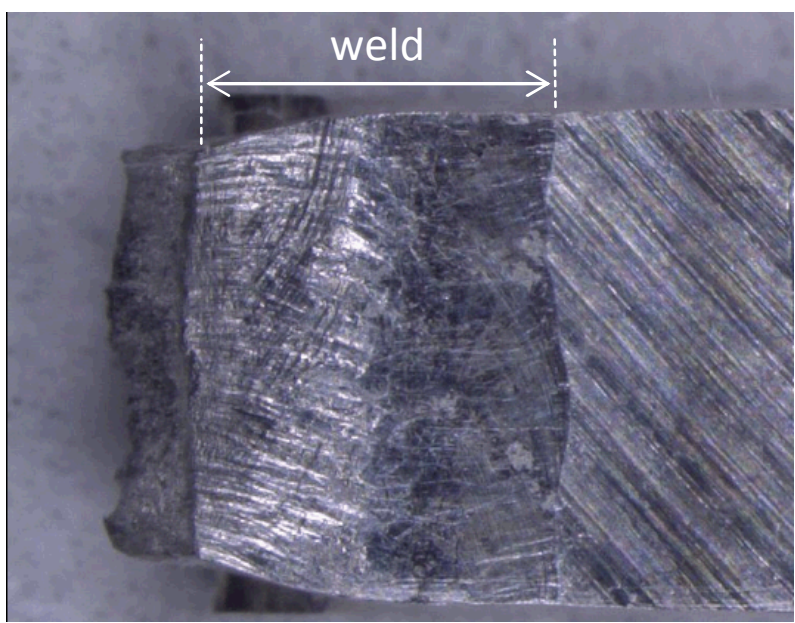

(f)

Figure 10: Close up photos of the necked regions of the mini tensile test bars: a) and b) side and top views of the base metal sample respectively; $c$ ) and d) side and top views of the milled cross-weld sample respectively; e) and f) side and top views of the fullthickness cross-weld sample respectively. Various magnifications; horizontal arrows indicate location of the welds. 

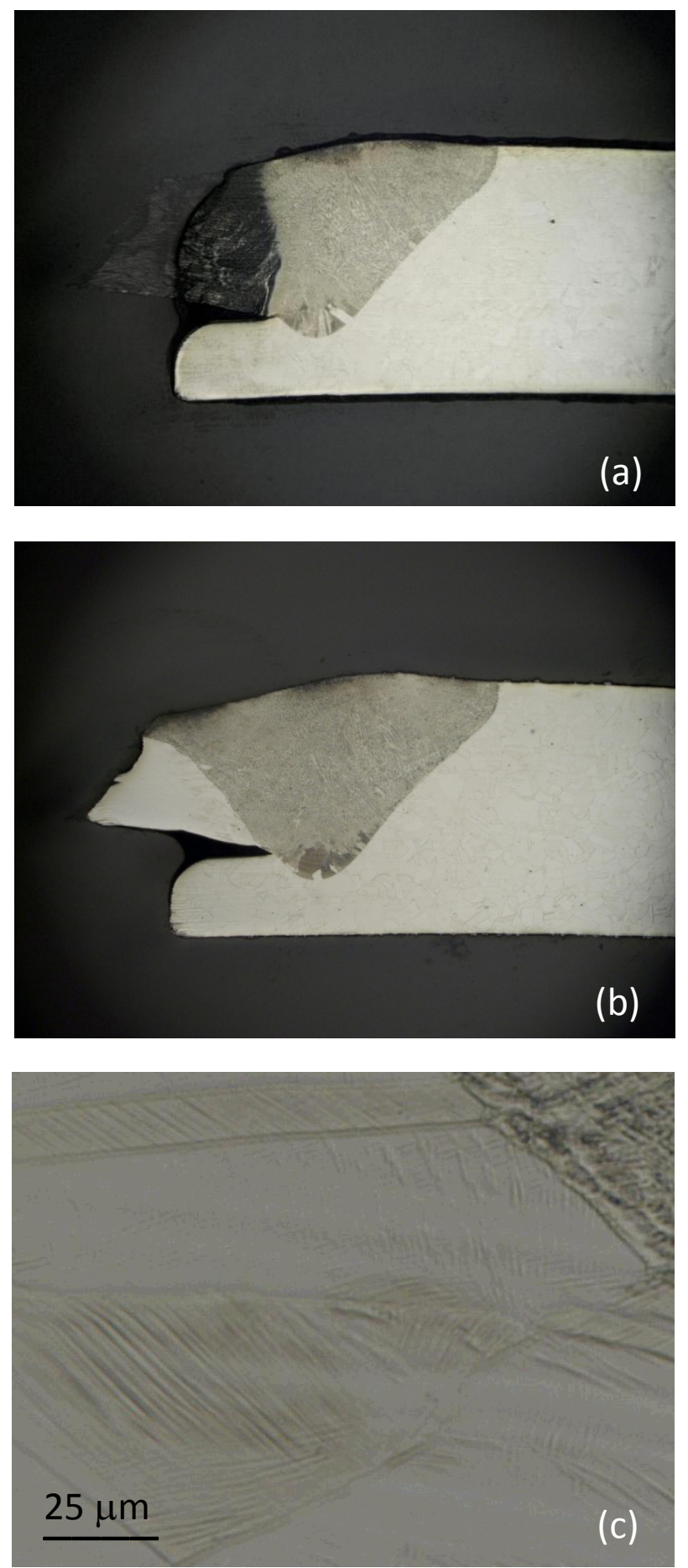

Figure 11: Full thickness mini sample after tensile testing (see Fig 10e before polishing). a) Sample after light polish of surface, showing deformation in the region directly above the unwelded portion of the step. b) After lapping the sample to a depth $\sim 1 \mathrm{~mm}$ below the surface to show necking and final failure location in the base metal. C) High magnification micrograph of the fusion line in the failed portion of the sample, showing deformation bands in the base metal. 


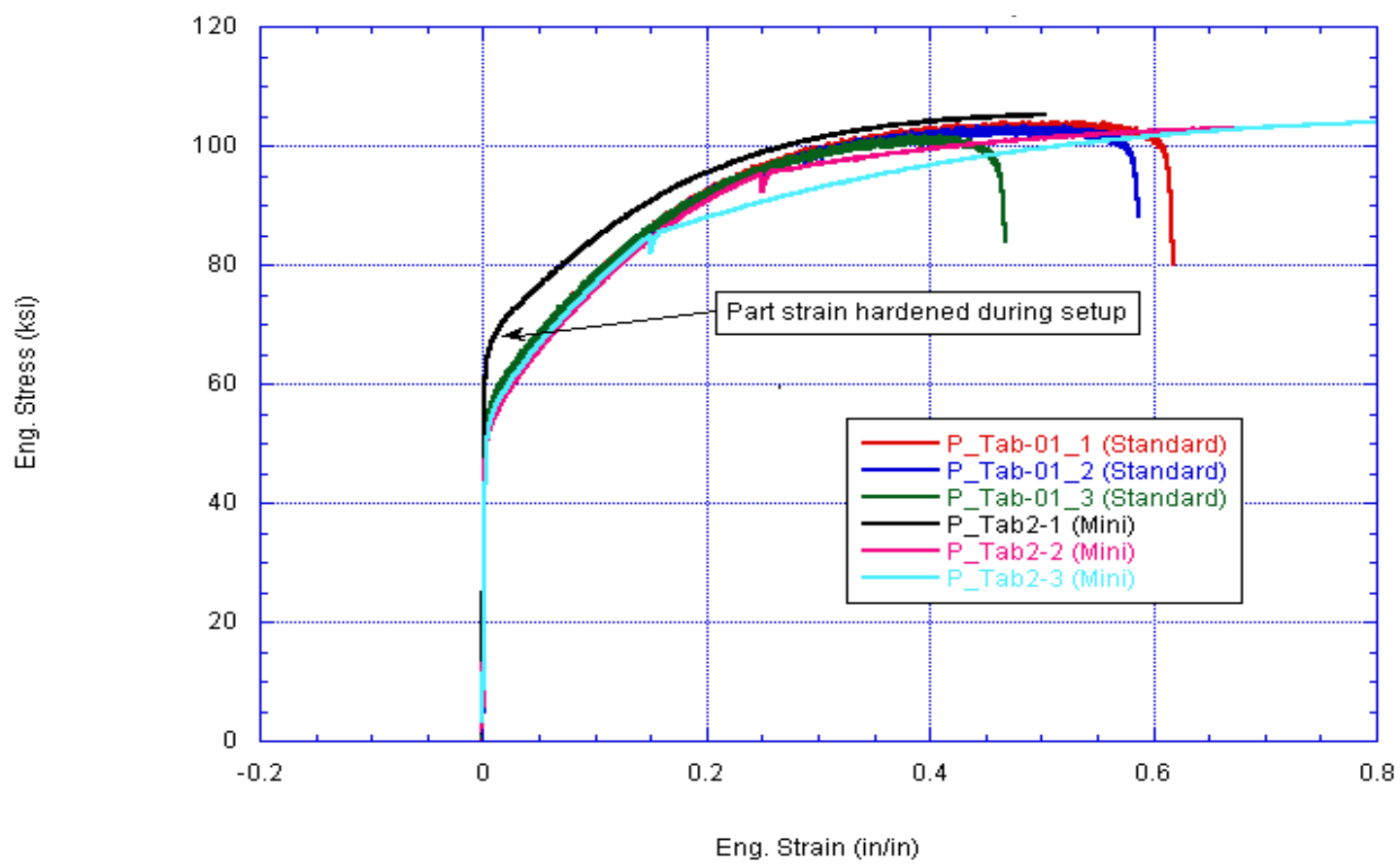

Figure 12: Base metal stress strain curves for the standard and mini tensile bars.

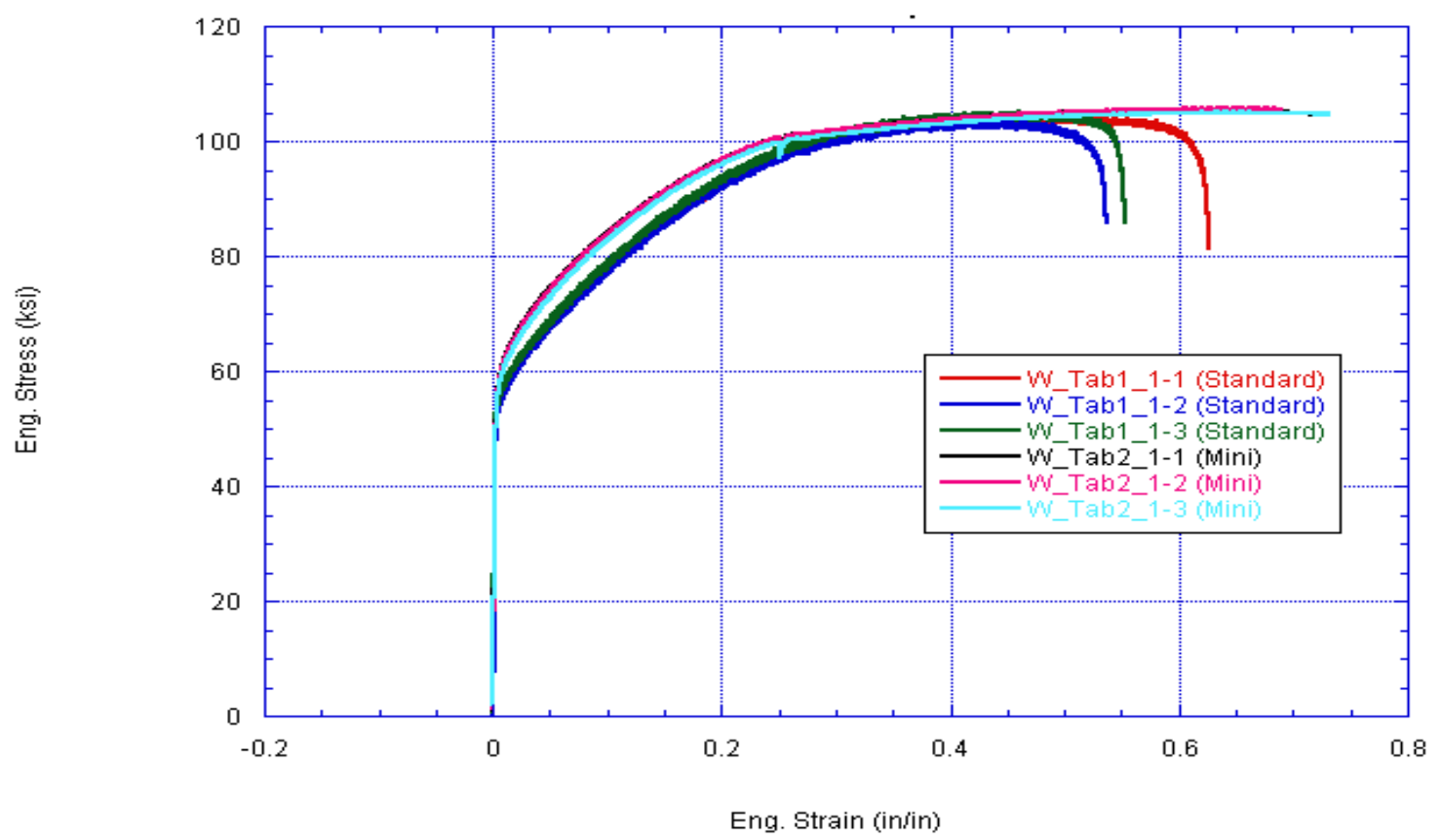

Figure 13: Milled/lapped cross-weld sample stress strain curves for the standard and mini tensile bars. 

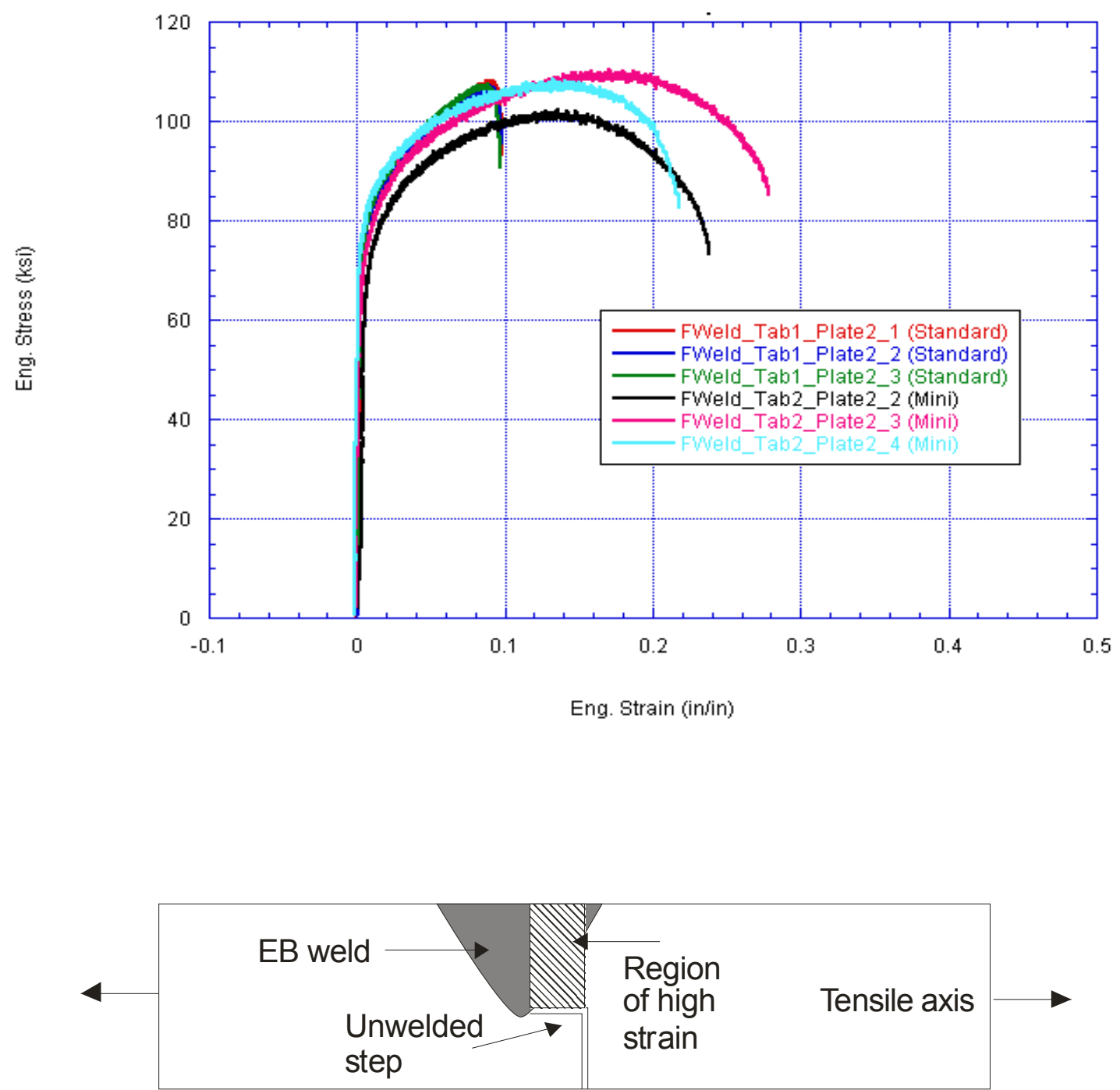

Figure 14: a) Full thickness cross-weld sample stress strain curves for the standard and mini tensile bars. b) Schematic drawing of the full thickness weld sample illustrating the high strain region directly above the unwelded portion of the step. 
LLNL-TR-654513

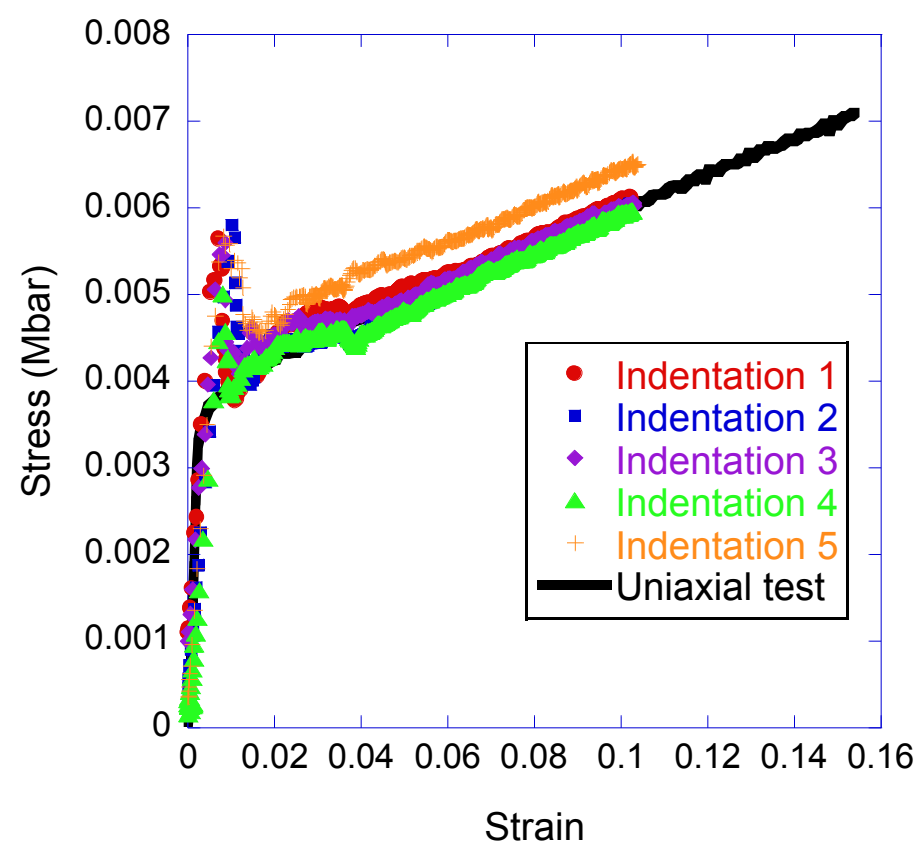

Figure 15: Stress-strain data from the 21-6-9 base metal. The stress-strain data from the indentation tests are compared to the uniaxial tests from report [5]. A Tabor factor of 3.6 is used to match the data.

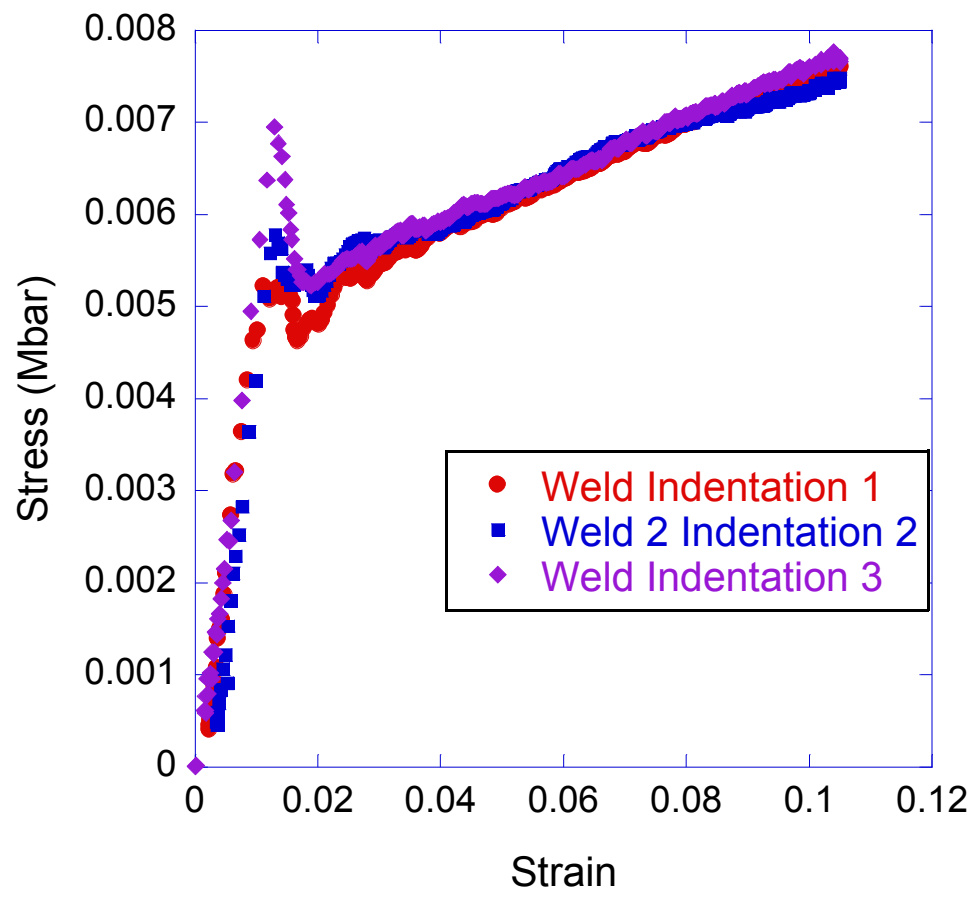

Figure 16: Stress-strain data from indentation tests for the 21-6-9 SS weld metal. The same Tabor factor of 3.6 is used. 


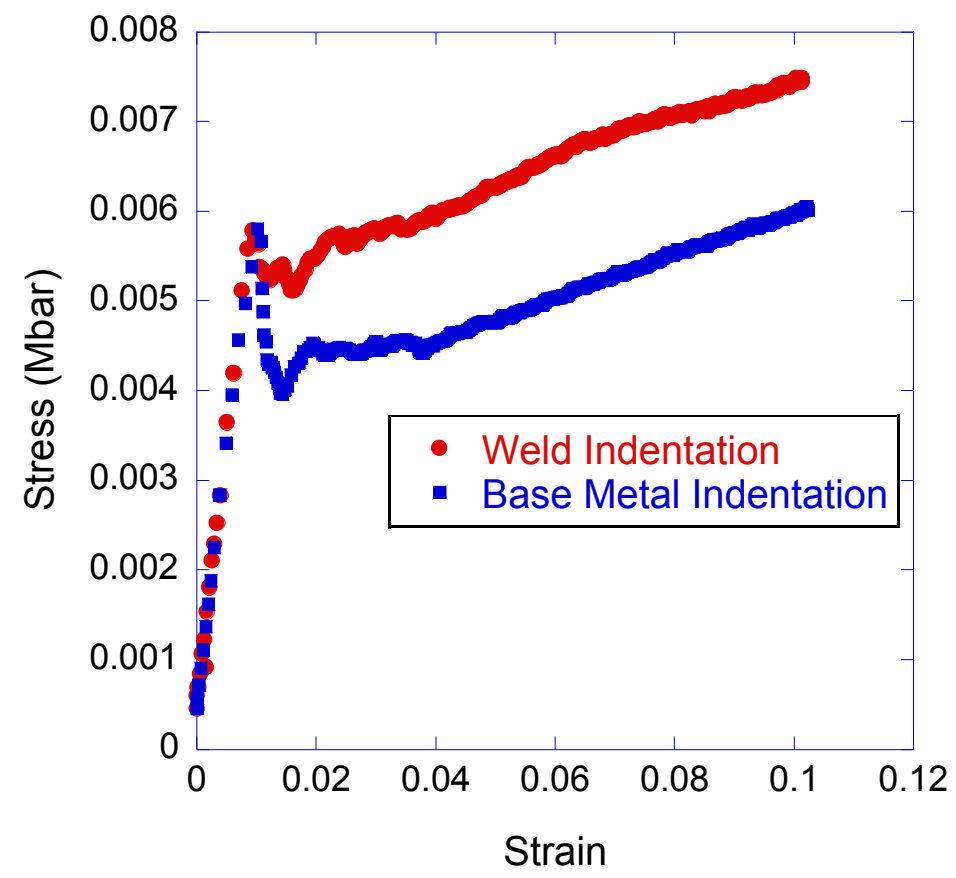

Figure 17: Comparison of stress-strain data from indentation tests for the 21-6-9 SS weld and base metal. The Tabor factor of 3.6 is used.

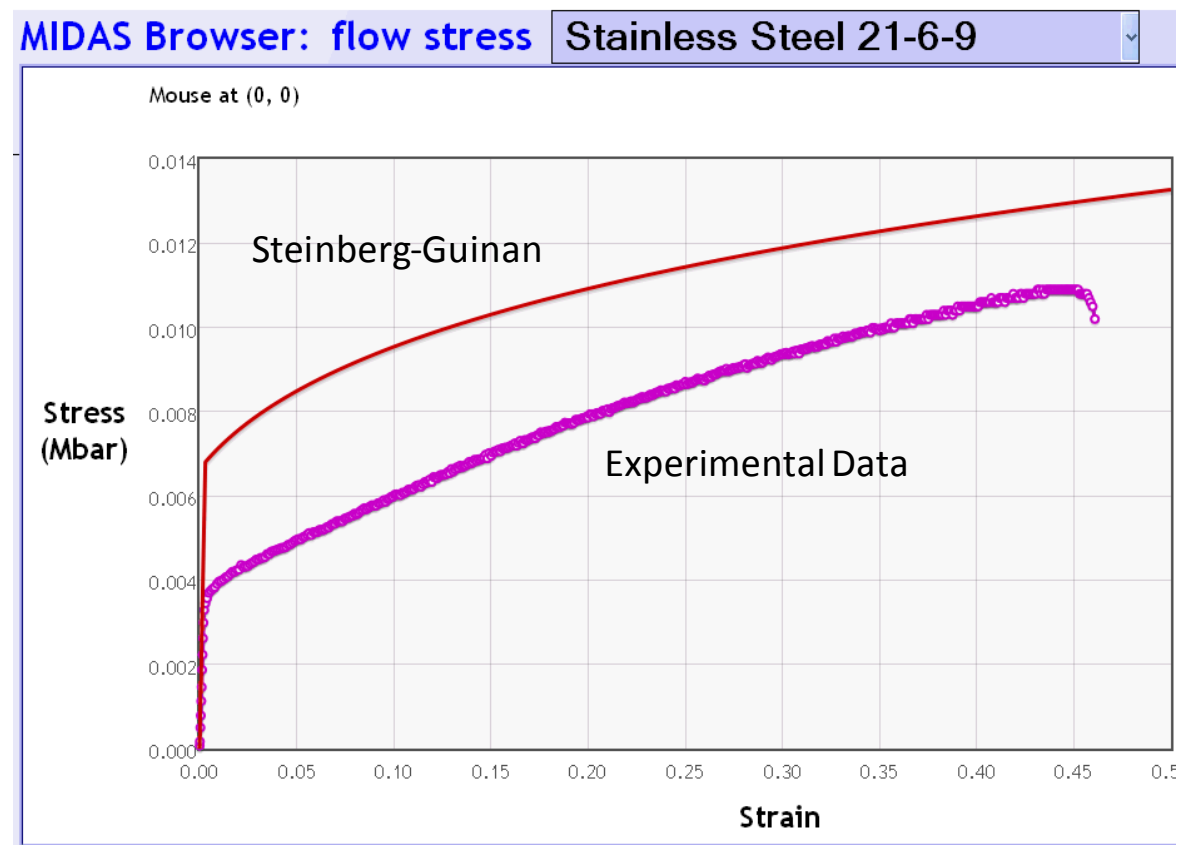

Figure 18: Comparison of the published Steinberg-Guinan parameters (optimized for high strain rates) to the experimental data of this study for annealed 21-6-9 SS base metal measured at quasi-static strain rates. 


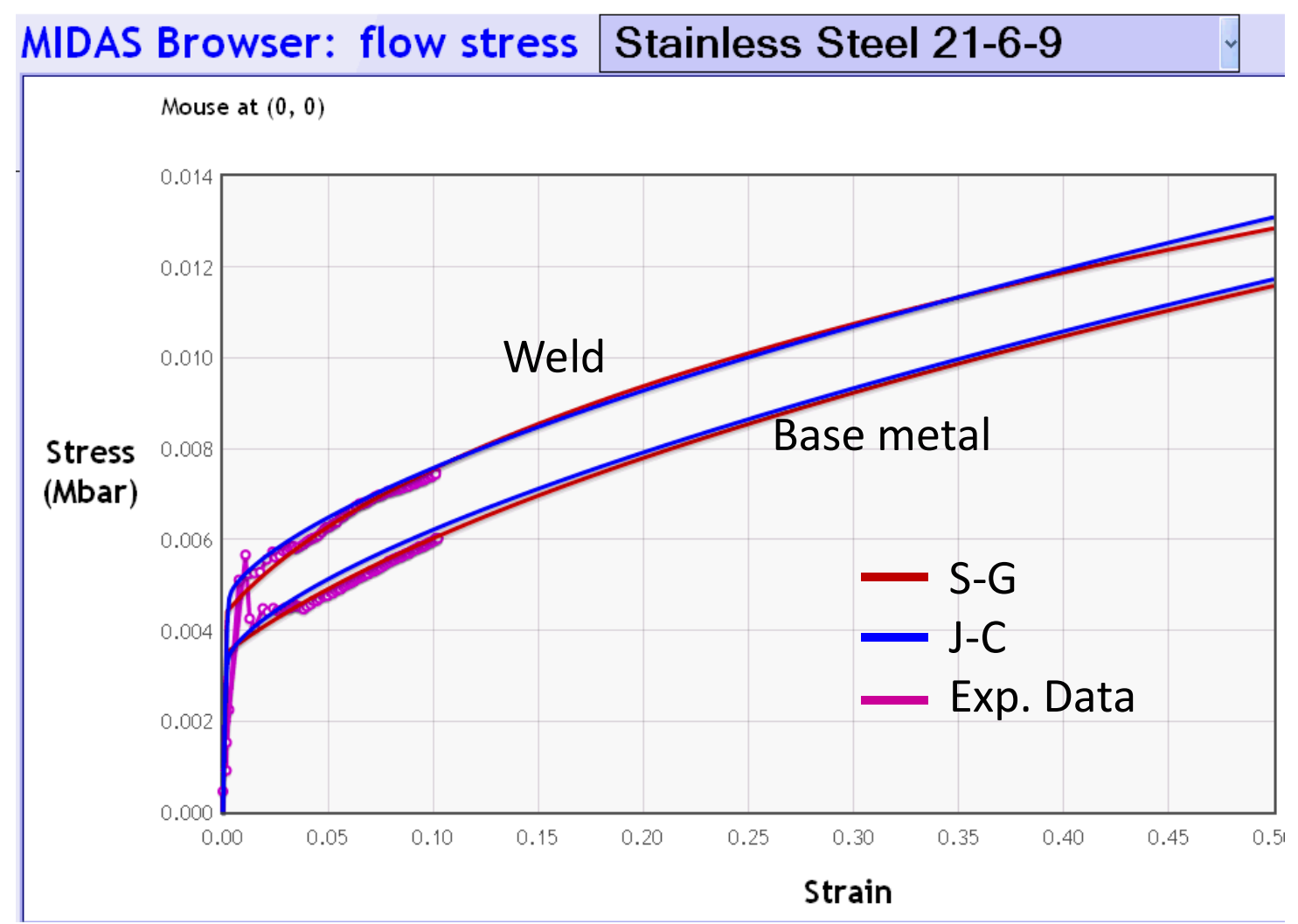

Figure 19: Steinberg-Guinan (S-G) and Johnson-Cook (J-C) stress-strain curve fits for the 21-6-9 SS base metal and weld metal using MIDAS to extrapolate the material behavior to larger strains. Both fits are superimposed over the spherical indentation experimental data. 


\section{Appendix}

This appendix derives the relationship between the elastic portion of the stress-strain curve for a partial penetration step weld joint and Young's modulus of the material. Figure A1 shows the step weld configuration. Assuming bending of the sample does not have a measurable effect on the load-displacement curve, then the stiffness of the partial penetration step joint weld in a uniaxial tensile test will be less than that of the full thickness welded sample, due to the reduced thickness of the $L_{2}$ segment. Further assuming that the modulus of elasticity, $E$, is constant for the different portions of the tensile bar then the following relationship can be derived from Hook's law ( $\sigma=\varepsilon \mathrm{E}$, where $\sigma$ is the stress and $\varepsilon$ is the strain in the sample):

$$
E=P L_{1} /\left(A_{1} * \Delta L_{1}\right)=P L_{2} /\left(A_{2} * \Delta L_{2}\right)=P L_{3} /\left(A_{3} * \Delta L_{3}\right), \quad \text { eq. } A 1
$$

where $P$ is the applied load, $\Delta L_{i}$ is the displacement, and $A_{i}$ is the cross sectional area of the $i_{\text {th }}$ segment. The cross sectional area of the sample is the width of the sample, $w$, multiplied by the respective thickness of the sample, i.e., $A_{i}=w t_{i}$.

A second relationship exists between the total displacement of the sample measured by the extensometer, $\Delta \mathrm{L}$, and the individual displacements for the three segments:

$$
\Delta \mathrm{L}=\Delta \mathrm{L}_{1}+\Delta \mathrm{L}_{2}+\Delta \mathrm{L}_{3} \quad \text { eq. } \mathrm{A} 2
$$

For a sample with the extensometer positioned over the weld such that $L_{1}=L_{3}$, the following relationship can be derived to relate the modulus of the material to the slope of the loaddisplacement curve and the step joint geometric configuration:

$$
E=(\Delta P / \Delta L) *\left(A_{1} L_{2}+2 L_{1} A_{2}\right) /\left(A_{1} A_{2}\right) \quad \text { eq. } A 3
$$

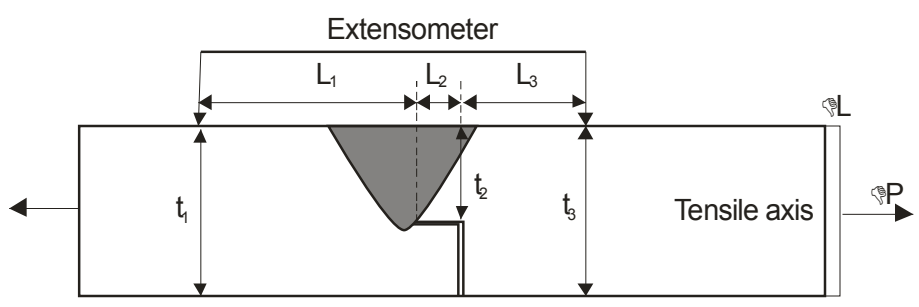

Figure A1: Schematic drawing of a step-weld joint being pulled in uniaxial tension. A region of high strain exists directly above the unwelded portion of the step with length $L_{2}$, and cross sectional area $t_{2}{ }^{*} w$, where $w$ is the width of the sample. 